\title{
Structural Basis and Designing of Peptide Vaccine using PE-PGRS Family Protein of Mycobacterium ulcerans - An Integrated Vaccinomics Approach
}

\author{
Zulkar Nain', Mohammad Minnatul Karim', Monokesh Kumer Sen² and Utpal Kumar Adhikari* \\ 'Department of Biotechnology and Genetic Engineering, Faculty of Biological Sciences, \\ Islamic University, Kushtia-7003, Bangladesh \\ ${ }^{2}$ School of Medicine, Western Sydney University, Locked Bag 1797, Penrith, NSW-275I, Australia \\ *Corresponding author (u.adhikari@westernsydney.edu.au)
}

\begin{abstract}
Buruli ulcer is an emerging-necrotizing skin infection, responsible for permanent deformity if untreated, caused by the pathogen Mycobacterium ulcerans (M. ulcerans). Despite this debilitating condition, no specific disease-modifying therapeutics or vaccination is available. Therefore, we aimed to design an effective multi-epitope vaccine against $M$. ulcerans through an integrated vaccinomics approach. Briefly, the highest antigenic PE-PGRS protein was selected from which the promiscuous $T$ - and B-cell epitopes were predicted. After rigorous assessment, 15 promising $C T L, H T L$ and LBL epitopes were selected. The identified T-cell epitopes showed marked interactions towards the HLA binding alleles and provided $99.8 \%$ world population coverage. Consequently, a vaccine chimera was designed by connecting these epitopes with suitable linkers and adjuvant (LprG). The vaccine construct was antigenic and immunogenic as well as non-allergenic; hence, subjected to homology modelling. The molecular docking and dynamic simulation revealed strong and stable binding affinity between the vaccine and TLR2 receptor. The binding energy $(\Delta G)$ and dissociation constant $\left(K_{d}\right)$ were $-15.3 \mathrm{kcal} / \mathrm{mol}$ and $5.9 \times 10^{-12} \mathrm{M}$, respectively. Further, disulfide engineering was applied to improve vaccine' stability and higher expression in Escherichia coli KI2 system was ensured by codon optimization and cloning in silico.The computer-simulated immune responses were characterized by higher levels of IgM and IgG antibodies, helper T-cells with increased IFN- $\gamma$ production, and macrophage activity crucial for immunity against $M$. ulcerans. Therefore, our data suggest that, if the designed vaccine is validated experimentally, it will prevent Buruli ulcer by generating robust immune response against $M$. ulcerans.
\end{abstract}

Keyword: Buruli ulcer; Mycobacterium ulcerans; PE-PGRS protein; Multi-epitope vaccine; Skin disease; Immunoinformatics; Bioinformatics

\footnotetext{
Abbreviations

$\Delta \mathrm{G}$, binding free energy; 3D, three-dimensional; Al, aliphatic index; BCG, Bacillus Calmette-Guérin; CAl, codon adaptation index; CTL, cytotoxic T-lymphocyte; DC, dendritic cells; GC, guanine-cytosine; GRAVY, grand average of hydropathicity; HLA, human leukocytes antigen; HTL, helper T-lymphocyte; IFN- $\gamma$, interferongamma; IgG, immunoglobulin G; IgM, immunoglobulin M; II, instability index; IL, interleukin; IMG/M, Integrated Microbial Genomes \& Microbiomes; Kd, dissociation constant; LBL, linear B-lymphocyte; MCS, multiple cloning site; MD, molecular dynamics; MHC, major histocompatibility complex; MW, molecular weight; NCBI, national center for biotechnology information; PE-PGRS, proline-glutamate polymorphic GC-rich sequence; RMSD, root mean square deviation; RMSF, root mean square fluctuation; SSL3, Staphylococcal superantigen-like protein 3; Theoretical PI, theoretical isoelectric point; TLR, toll-like receptor; TM, transmembrane; and TNF- $\alpha$, tumor necrosis factor-alpha.
} 
bioRxiv preprint doi: https://doi.org/10.1101/795146; this version posted October 7, 2019. The copyright holder for this preprint (which was not certified by peer review) is the author/funder, who has granted bioRxiv a license to display the preprint in perpetuity. It is made available under aCC-BY-NC-ND 4.0 International license.

\section{Introduction}

Buruli ulcer is a neglected tropical disease of the skin characterized by chronic skin lesions and tissue necrosis leading to permanent cosmetic deformity and functional disability affecting thousands of people worldwide (Pluschke and Röltgen 2015; Simpson et al. 2019; Barksby 2019). Despite being endemic to West and Central Africa (Johnson 2019), Buruli ulcer has been reported from more than 34 countries worldwide including countries from South America and Western Pacific regions (Pluschke and Röltgen 2015; Singh et al. 2019; Simpson et al. 2019). About $80 \%$ of cases were from West African countries i.e., Côte d'Ivoire, Ghana, Benin and Cameroon (Mitra AK 2017). However, there is no consensus on the current distribution of this mycobacterial disease, except for 12 countries which constitute 34,890 reported cases worldwide from 2007 to 2016 (Simpson et al. 2019). Buruli ulcer has become the third most common mycobacterial disease after tuberculosis and leprosy (Phillips et al. 2015; Huygen et al. 2009). Although it may affect everyone irrespective of ages but the risk is the highest in the children ( 15 years old) (Huygen et al. 2009) and aged people (>50 years old) (N'krumah et al. 2016).

Mycobacterium ulcerans (M. ulcerans) is the causative agent of Buruli ulcer (N'krumah et al. 2016; Singh et al. 2019; Simpson et al. 2019). The pathogen M. ulcerans has evolved from the fish pathogen M. marinum which rarely causes skin lesions in humans (Yip et al. 2007; Petrini 2006). The emergence of $M$. ulcerans has been associated by the acquisition of PMUM plasmid that encodes the gene for the production of mycolactone (Johnson 2019; George et al. 1999), a polyketide-derived diffusible exotoxin, that has cytotoxic and immunosuppressive properties responsible for chronic skin lesions (Adusumilli et al. 2005; Walsh et al. 2005; Hong et al. 2008) and destroying the immune cells before reaching the infection site (Pluschke and Röltgen 2015). This exotoxin (mycolactone) is the main virulence factor of M. ulcerans (George et al. 1999; Barksby 2019). However, the occurrence of Buruli ulcer is still perplexing due to the incomplete knowledge about the reservoirs and transmission pathways of $M$. ulcerans (Barksby 2019). A few lines of evidence has described that disease transmission is associated with contaminated water (Huygen et al. 2009; Singh et al. 2019; Sears and Hay 2015). Recent studies suggest that $M$. ulcerans uses different transmission vehicles in different geographic areas (Merritt et al. 2010). For example, aquatic insects in Benin contain M. ulcerans DNA which indicated their possible involvement in the transmission (Marsollier et al. 2002). Moreover, mosquitoes have been suspected of playing a detrimental role in bacterial transmission in Australia (Quek et al. 2007; Singh et al. 2019).

Buruli ulcer has become a major public health concern due to the lack of specific treatment and preventive measures (Simpson et al. 2019; Johnson 2019; Singh et al. 2019). Despite the effectiveness of antibiotics against Buruli ulcer, failures of treatment are common and the pathogen is prone to develop resistance (Phillips et al. 2015). In addition, there is no effective vaccination available for preventing Buruli ulcer (Phillips et al. 20I5). There are, however, considerable evidences that supported the feasibility of vaccine preparation against M. ulcerans (Huygen et al. 2009). To date, several attempts have been made to develop a potent vaccine against $M$. ulcerans but were resulted in a limited success (Tanghe et al. 2008; Hart, Hale, and Lee 2016; Coutanceau et al. 2006; Ravenel 1928). The only vaccine that is widely used to control Buruli ulcer is a live attenuated Mycobacterium bovis vaccine known as Bacillus CalmetteGuérin (BCG) vaccine. However, effectiveness of BCG vaccine against Buruli ulcer is found contradictory to some extent (Phillips et al. 2015; Ravenel 1928). In a recent study, for instance, no significant evidence was found in favor of BCG vaccine's protective effect against mild to severe form of Buruli ulcer (Phillips et al. 20I5). Besides, there are also 
bioRxiv preprint doi: https://doi.org/10.1101/795146; this version posted October 7, 2019. The copyright holder for this preprint (which was not certified by peer review) is the author/funder, who has granted bioRxiv a license to display the preprint in perpetuity. It is made available under aCC-BY-NC-ND 4.0 International license.

possible side-effects with the use of killed or live attenuated bacterial vaccines (Saadi, Karkhah, and Nouri 2017). For example, mycolactone-deficient attenuated $M$. ulcerans strain 5114 provides a short-term protection against infected mice (Fraga et al. 2012). Nevertheless, this attenuated strain may still retain factors which can hinder effective memory cell development (Hart, Hale, and Lee 2016). Furthermore, DNA vaccine encoding immunodominant Ag85A protein of M. ulcerans showed protection similar to BCG vaccination (Tanghe et al. 2008; Hart, Hale, and Lee 2016). These evidences are suggesting that the subunit vaccine could be an alternative in terms of safety, efficacy and specificity (Saadi, Karkhah, and Nouri 20I7; Yin et al. 2016).

The subunit vaccine contains the fragment(s) of antigenic proteins that can mimic the presence of the natural pathogen and generate immune response against the target pathogen (Saadi, Karkhah, and Nouri 2017). In 1985, the first epitope-based subunit vaccine was developed against cholera in Escherichia coli (Jacob et al. 1985), while many are still under development such as the vaccine for malaria, swine flue, influenza, and anthrax (Li et al. 20l4). Besides, some multi-epitope vaccines have even entered phase I clinical trial. For instance, survivin-derived multi-epitope cancer vaccine (EMD640744) used in patients with advanced tumors (L. Zhang 20I8; Lennerz et al. 20I4). Interestingly, multiple-component peptide vaccine are able to generate more protective immune response than the single component vaccine (Saadi, Karkhah, and Nouri 2017). Recently, in silico designing of multi-epitope vaccine against viruses, bacteria and parasites have become a commonplace due to the ease of access to bioinformatics tools and servers (Adhikari and Rahman 2017; A. Ali et al. 2019; M. Ali et al. 2017; Ikram et al. 2018; Mirza et al. 2016; Yasmin and $\mathrm{Nabi}$ 2016). Conceptually, multi-epitope vaccines have some advantages over classical (i.e., live and attenuated) and single-epitope vaccines (Lin et al. 2016; Lu et al. 2017; Saadi, Karkhah, and Nouri 2017). For example, it can be manipulated in a variety of ways such as combining T- and B-cell epitopes from same or different antigen(s) derived from same source. Besides, unwanted component that produces toxic or allergenic reactions can be eliminated. Furthermore, adjuvant can be added to enhance the immunogenic potency (Saadi, Karkhah, and Nouri 2017). Therefore, it can be hypothesised that a well-designed multi-epitope vaccine with such advantages could be a potent prophylactic against $M$. ulcerans.

In this study, M. ulcerans proteome was explored to determine the highest antigenic protein(s) followed by the prediction of different $\mathrm{T}$ - and B-cell epitopes with their corresponding major histocompatibility complex (MHC) alleles. These epitopes were evaluated for their immunological profile. Finally, a multi-epitope vaccine was designed using the most potent epitopes with appropriate adjuvant and linkers. The primary sequence of the vaccine construct was used for the immunogenic and physiochemical profiling followed by homology modelling. The crude three-dimensional (3D) structure was then refined and subjected to disulfide engineering for stability enhancement. The binding interaction and stability of the vaccine-receptor complex were analyzed by molecular docking and dynamic simulation, respectively. Moreover, immune responses induced by the vaccine antigen were simulated to investigate the real-life potency. Finally, the vaccine codon was optimized for $E$. coli system and in silico cloning was performed. The computational workflow of the study is graphically illustrated in Fig. I. 


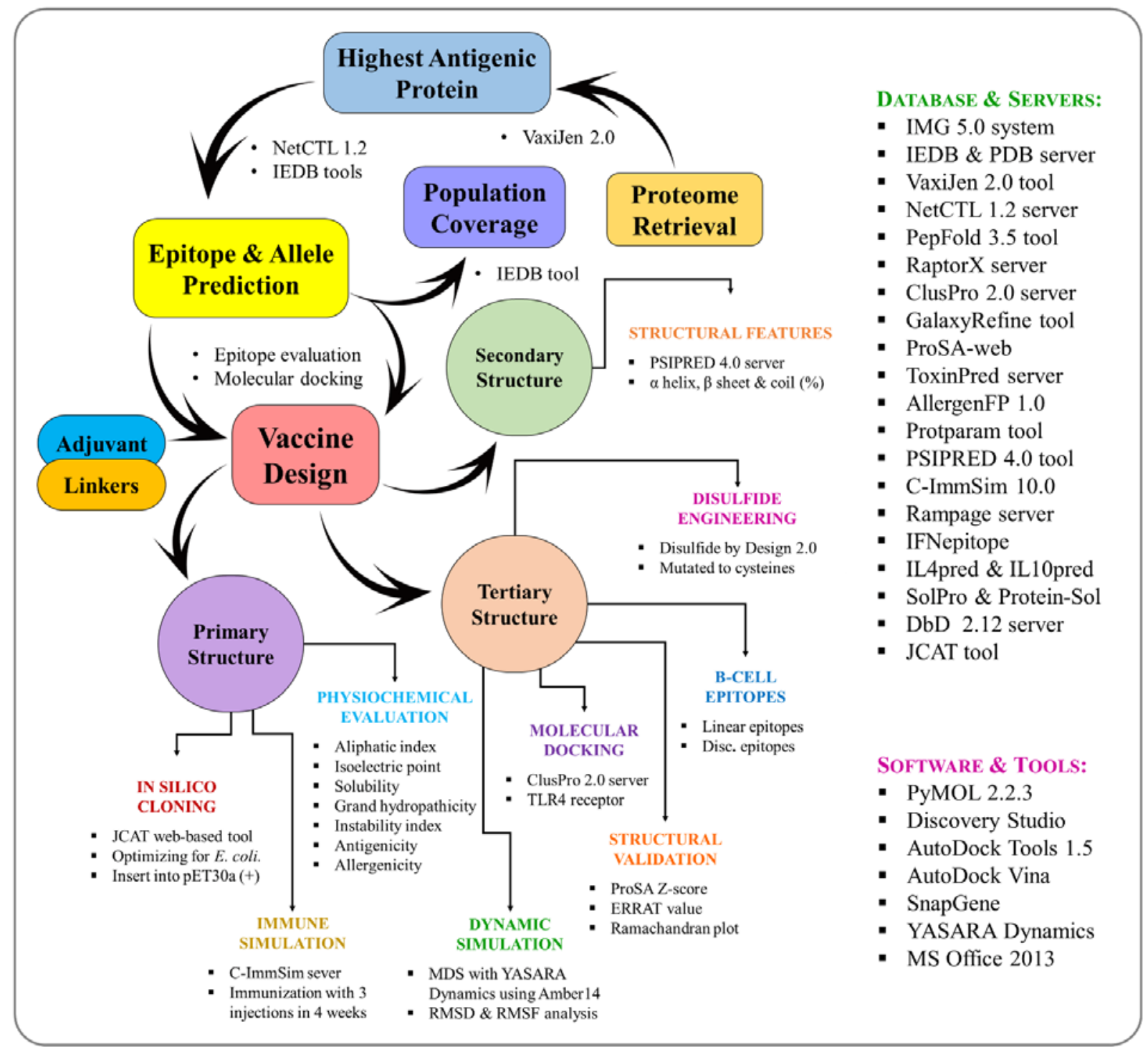

Fig. I: The overall experimental workflow used to develop a multi-epitope vaccine against $M$. ulcerans.

\section{Materials and Methods}

\section{I. Immunoinformatic study of the antigen}

2.I.I. Proteome retrieval and prediction of antigenicity and transmembrane helix: The whole proteome of $M$. ulcerans Agy99 was collected from Integrated Microbial Genomes \& Microbiomes (IMG/M) v5.0 system (Chen et al. 2019). Fed by the national center for biotechnology information (NCBI) database, this system integrates the draft and complete genomes of Archaea, Bacteria and Eukaryota which can be retrieved with or without protein homolog in any target species (Markowitz et al. 2012). Vaccine candidates should not have homology with human proteins to avoid autoimmune response (Monterrubio-López, González-Y-Merchand, and Ribas-Aparicio 2015). Therefore, human protein homologs were avoided during the proteome retrieval. Since for an effective peptide vaccine the target protein should be able to induce an immune response, the antigenicity of all protein sequences included in the proteome was predicted using the VaxiJen v2.0 server (Doytchinova and Flower 2007) with 0.5 threshold. This server uses auto cross-covariance transformation method to maintain 70-89\% accurate prediction (Doytchinova and Flower 2007). Proteins with transmembrane helices are often created difficulty in purification (Monterrubio-López, González-YMerchand, and Ribas-Aparicio 2015); hence, they are not desired in target protein selection. The top-ten antigenic 
bioRxiv preprint doi: https://doi.org/10.1101/795146; this version posted October 7, 2019. The copyright holder for this preprint (which was not certified by peer review) is the author/funder, who has granted bioRxiv a license to display the preprint in perpetuity. It is made available under aCC-BY-NC-ND 4.0 International license.

proteins were further subjected to transmembrane (TM) helix prediction with TMHMM v2.0 server (Krogh et al. $2001)$.

2. I.2. Prediction and assessment of cytotoxic T-lymphocyte (CTL) epitopes. Cytotoxic T-cells play key role in specific antigen recognition that made CTL epitopes essential for coherent vaccine design (Chaudhri et al. 2009). Therefore, the CTL epitopes present in the selected protein were determined using the NetCTL vI.2 server with 0.5 threshold (Larsen et al. 2007). This server predicts CTL epitopes (9-mer) based on the MHC-I binding peptides, Cterminal cleavage, and TAP transport efficiency through artificial neural networks and weight matrix (Larsen et al. 2007). The IEDB MHC-I binding tool was used to anticipate the MHC-I binding alleles for each CTL epitope based on the CONSENSUS method (Moutaftsi et al. 2006). In this study, we considered percentile rank score $\leq 2$; since the lower the rank, the higher the affinity (Moutaftsi et al. 2006). Vaccine components should be antigenic and immunogenic; simultaneously, it should be devoid of allergic and toxic reaction. So, each CTL epitope was evaluated for their individual antigenic, immunogenic, allergenic and toxic profiles. Therefore, the immunogenicity and antigenicity were evaluated with IEDB MHC-I immunogenicity tool (Calis et al. 20I3) and Vaxilen v2.0 server (Doytchinova and Flower 2007), respectively. Furthermore, the AllergenFP vl.0 server (Dimitrov et al. 20l4)was used for allergenicity and ToxinPred (Gupta et al. 2013) for toxicity prediction. Herein, the AllergenFP vl.0 applies novel alignment-free descriptor-based fingerprint approach for ensuring 88.9\% prediction accuracy (Dimitrov et al. 20I4) while ToxinPred works based on different peptide properties using machine learning techniques accompanied with quantitative matrix (Gupta et al. 2013).

2. I.3. Prediction and evaluation of helper T-lymphocyte (HTL) epitopes. Being the most important cells in adaptive immunity, helper T-cells influence B-cells to secrete antibodies, macrophages to phagocyte pathogens, and cytotoxic T-cells to eliminate targeted parasitized cells (Zhu and Paul 2008), that are important in cell-mediated immunity against M. ulcerans (Fraga et al. 20II). Therefore, vaccine construct should contain HTL epitopes from rational perspective. Consequently, the selected protein was submitted to IEDB MHC-II binding tool (Wang et al. 2010) for the prediction of I5-mer HTL epitopes along with their respective binding alleles using the CONSENSUS method (Wang et al. 2008) The percentile rank threshold $\leq 2$ was considered. Helper T-cells produce different cytokines such as interferon-gamma (IFN- $\gamma$ ), interleukin-4 (IL-4) and IL- 10 resulting in the activation of cytotoxic Tcells and other immune cells such as macrophages (Luckheeram et al. 2012). Therefore, cytokine-inducing HTL epitopes are crucial for vaccine development. Consequently, IFNepitope server was applied to predict IFN- $\gamma$ producing HTL epitopes with Motif and SVM based hybrid method and IFN- $\gamma$ versus Non-IFN- $\gamma$ model (Dhanda, Vir, and Raghava 20I3). On the other hand, IL-4 and IL-I0 inducing properties were predicted using IL4pred (Dhanda et al. 20I3) and ILIOpred (Nagpal et al. 2017) servers, respectively. The IL4pred and ILIOpred operations were carried out based on SVM method with threshold value 0.2 and -0.3 , respectively.

\section{I.4. Prediction and assessment of linear B-lymphocyte (LBL) epitopes. A surface receptor of B-cell recognizes}

B-cell epitopes, resulting the generation of antigen-specific immunoglobulins (Cooper 20I5). Therefore, designing a vaccine consisting of B-cell epitopes can play an essential role in adaptive immunity. There are two types of B-cell epitopes, namely, linear and conformational epitopes (J. Zhang et al. 20I4). In vaccine construction, only linear B-cell epitopes can be incorporated into the multi-peptide sequence (Oscherwitz 2016; Dormitzer, Ulmer, and Rappuoli 
bioRxiv preprint doi: https://doi.org/10.1101/795146; this version posted October 7, 2019. The copyright holder for this preprint (which was not certified by peer review) is the author/funder, who has granted bioRxiv a license to display the preprint in perpetuity. It is made available under aCC-BY-NC-ND 4.0 International license.

2008), hence, predicted using iBCE-EL server (Manavalan et al. 20I8). This server predict I2-mer LBL epitopes by default using a novel ensemble learning framework consisting of two independent predictors, namely, extremely randomized tree and gradient boosting classifiers (Manavalan et al. 2018) The predicted B-cell epitopes were further assessed through Vaxilen v2.0 (Doytchinova and Flower 2007), AllergenFP vl.0 (Dimitrov et al. 20I4) and ToxinPred (Gupta et al. 20I3) server for their antigenic, allergenic and toxic profiles, respectively.

2. I.5. Peptide modelling and molecular docking studies. Molecular docking is a computational method used to measure the binding affinity between protein and ligand molecule. The selected epitopes were docked into their respective human leukocytes antigen (HLA) binding alleles to further prove their efficiency to be a part of multi-epitope vaccine. Initially, CTL and HTL epitopes were modeled using PEP-FOLD v3.0 server (Lamiable et al. 2016) with sOPEP sorting scheme in 200 simulations. This server was designed to predict the conformations of small peptides (5-50 amino acids) based on Forward Backtrack/Taboo Sampling algorithm (Lamiable et al. 2016). The crystal structure of the alleles with co-crystallized ligands was then downloaded from RCSB Protein Data Bank (https://www.rcsb.org/). The structures were processed with Discovery Studio followed by the generation of a grid box around their native active sites with AutoDock tools (Morris et al. 2009). For CTL epitopes, allele HLA-B*0702, HLA-A*II0I, HLA $A * 0 I 0 I$ and HLA-B*390I were considered while DRBI*IIOI, DQAI*030I, and DRBI*0IOI were used for HTL epitopes. Finally, the docking simulation was performed using AutoDock Vina (Trott and Olson 2009). As a positive control, the co-crystallized ligands were considered. The PyMOL Molecular Graphics System v2.2.3 was used to make docked complex and visualized in BIOVIA Discovery Studio 2017 (https://3dsbiovia.com).

2. I.6. Estimation of population coverage. The distribution and expression of HLA alleles vary according to the ethnicities and regions throughout the world (Adhikari, Tayebi, and Rahman 2018), thus, influence the successful development of an epitope-based vaccine (Bui et al. 2006). The population coverage by the designed vaccine was calculated with the IEDB Population Coverage tool (Bui et al. 2006). For this purpose, selected CTL and HTL epitopes and corresponding HLA binding alleles were considered. This tool estimates population coverage of each epitope for different regions of the world based on the distribution of human MHC binding alleles. In this study, however, areas of particular importance regarding our pathogen will be emphasized such as $M$. ulcerans endemic regions and areas of Buruli ulcer occurrence.

\subsection{Designing and evaluation of multi-epitope vaccine}

2.2.I. Mapping of vaccine construct. The multi-epitope vaccine was designed by joining adjuvant, T-cell and B-cell epitopes with appropriate linkers as described previously (Nezafat et al. 2016; Khatoon, Pandey, and Prajapati 2017). An adjuvant is an immunogenic component which enhance the vaccine's immunogenicity, hence, should be chosen carefully (Coffman, Sher, and Seder 2010). For example, it should have affinity towards immune receptor such toll-like receptor (TLR) receptor (Kaisho and Akira 2002). The TLR2 on epidermal keratinocytes are actively involved in the internalization of $M$. ulcerans and concomitant innate immune response. Therefore, TLR2 is essential for provoking an immune response against M. ulcerans (Lee et al. 2009). In addition, PE-PGRS protein interacts with TLR2 on macrophages and antigen presenting cells such as dendritic cells (Brennan 2017). Moreover, TLR agonists (i.e., lipoproteins, lipopolysaccharides, monophosphoryl lipid A, and mannan-protein) are well-known to be used as vaccine adjuvants (Gnjatic, Sawhney, and Bhardwaj 2010; Kumar, Sunagar, and Gosselin 2019). The mycobacterial lipoprotein 
bioRxiv preprint doi: https://doi.org/10.1101/795146; this version posted October 7, 2019. The copyright holder for this preprint (which was not certified by peer review) is the author/funder, who has granted bioRxiv a license to display the preprint in perpetuity. It is made available under aCC-BY-NC-ND 4.0 International license.

LprG is a prominent TLR2 agonist (Gehring et al. 2004). Therefore, M. ulcerans derived LprG (GenBank: ABL04283) was taken as the adjuvant in this study (Stinear et al. 2007). The EAAAK linker facilitates the effective separation of bifunctional fusion protein domains (Arai et al. 200I), therefore, utilized to integrate the adjuvant and first HTL epitope. For the efficient recognition of epitopes within the vaccine, GPGPG and AAY linkers were used to merge HTL and CTL epitopes, respectively. The LBL epitopes were added together with bi-lysine (KK) linker to preserve their independent immunogenic activities as shown before (Gu et al. 20I7).

2.2.2. Primary and secondary structural analysis. The physicochemical properties of the designed vaccine construct, including molecular weight (MW), theoretical isoelectric point (theoretical PI), instability index (II), aliphatic index (Al), and grand average of hydropathicity (GRAVY), in vitro and in vivo half-life were assessed using ProtParam server (Wilkins et al. 1999). Moreover, antigenic and immunogenic profiles were predicted with VaxiJen v2.0 server and IEDB Immunogenicity tool, respectively. The vaccine protein should be free from allergic reaction. Therefore, AllergenFP vI.0 server was used to predict the allergenic nature of the construct. Furthermore, the solubility of the construct upon overexpression in E. coli host was predicted by SOLpro tool (Magnan, Randall, and Baldi 2009). This server use I0-fold cross-validation method and provides more than $74 \%$ accurate prediction. We also use Protein-Sol web-tool to further clarify the solubility of the chimeric protein (Hebditch et al. 2017). Finally, the secondary structural features were revealed using the primary with PSIPRED 4.0 server that uses two feed-forward neural networks for precise prediction based on position-specific scoring matrix (Buchan et al. 20I3).

2.2.3. Tertiary structure modelling. The $3 D$ structure is the lowest energy state of a protein which provides the maximum stability through proper twisting and bending. RaptorX server was used to predict the tertiary structure of the vaccine construct (Källberg et al. 20I2). It predicts 3D protein model based on multiple-template threading (MTT) and provides some confidence scores as a quality indicator. For example, $p$-value for relative global quality, global distance test (GDT), and unnormalized GDT (uGDT) for absolute global quality, and modelling error at each residue (Källberg et al. 20I2). Finally, the tertiary structure was visualized with BIOVIA Discovery Studio 2017.

2.2.4. Refinement and validation of tertiary structure. The crude vaccine model should be refined to carry out further evaluation. For this purpose, we used GalaxyRefine web-server (Ko et al. 20I2) which uses CASPIO tested refinement method (Nugent, Cozzetto, and Jones 2014). It rehashed structure perturbation followed by overall structural relaxation through dynamics simulation (Pandey, Bhatt, and Prajapati 2018). Further, refined structure needs to be validated based on experimentally validated 3D protein structure. Therefore, the refined vaccine protein was applied in ProSA-web (Wiederstein and Sippl 2007) which provides an overall quality score for a given structure. The quality score outside the usual range of native proteins indicates possible errors in the predicted protein structure. Besides, ERRAT server (Colovos and Yeates 1993) was used to evaluate the statistics of non-bonded interactions. Ramachandran plot was created with the RAMPAGE server (Ramachandran, Ramakrishnan, and Sasisekharan 1963; Lovell et al. 2003) where PROCHECK principle is applied to validate protein structure based on energetically allowed and disallowed dihedral angles psi $(\psi)$ and phi $(\varphi)$ of amino acid residues (Laskowski et al. 1993). The crude vaccine model was also subjected to validation as a control for refined model. 
2.2.5. Screening for conformational B lymphocyte epitopes. Since antibody-mediated humoral immunity initiates when B-cells meet their epitopic counterparts, vaccine protein should contain B-cell epitopes. IEDB ElliPro tool (Ponomarenko et al. 2008) was applied for the prediction of conformational B-cell epitopes in the final vaccine protein using default setting (i.e., 0.5 min-score and $6 \AA$ max-distance). The ElliPro predicts epitopes through an approximation of protein shape, residual protrusion index (PI) and neighbor residue clustering (Ponomarenko et al. 2008).

2.2.6. Disulfide engineering of the vaccine protein. Two adjacent protein chains can be bridged with covalent bond through disulfide engineering which increases the structural stability of a protein (Khatoon, Pandey, and Prajapati 2017; Pandey, Bhatt, and Prajapati 2018). Therefore, the refined vaccine model was submitted to Disulphide by Design 2.12 server (Craig and Dombkowski 20I3). This web-platform identifies residue pairs in a given protein that can be suitable for covalent modifications based on their energy score and $\chi^{3}$ value. For disulfide bridges to be formed, the energy score should be lower than $2.2 \mathrm{kcal} / \mathrm{mol}$ and $\chi^{3}$ angle should be within -87 to +97 degree as previously optimized (Craig and Dombkowski 20I3). Finally, the potential residue pairs were selected and mutated to cysteine residues to allow bridging between them using 'Create/View Mutant' function of the Disulfide by Design 2.12 server.

2.2.7. Docking between vaccine protein and TLR2 receptor. Toll-like receptor 2 (TLR2) plays an important role in triggering immune responses to M. ulcerans (Lee et al. 2009). In addition, the adjuvant LprG added in the vaccine protein was a TLR2 agonist. Therefore, TLR2 (PDB ID: 3a7c) was considered as the docking receptor, hence, retrieved from the RCSB PDB database (Berman et al. 2000) and the vaccine protein was used as a ligand. Finally, the vaccine protein and TLR2 immune receptor were submitted to the ClusPro v2.0 server for molecular docking (Kozakov et al. 2017). The ClusPro server calculates the binding affinity $(\Delta \mathrm{E})$ according to the following equation:

$$
\Delta \mathrm{E}=0.40 \times \mathrm{E}_{\text {rep }}+-0.40 \times \mathrm{E}_{\text {att }}+600 \times \mathrm{E}_{\text {elec }}+1.00 \times \mathrm{E}_{\text {DARS }}
$$

Where, $E_{\text {rep }}$ and $E_{\text {attr }}$ denote the repulsive and attractive contributions to the van der Waals interaction energy, respectively, $E_{\text {elec }}$ defines the electrostatic energy term, and $E_{D A R S}$ is a pairwise structure-based potential constructed by the Decoys as the Reference State (DARS) approach (Chuang et al. 2008).

The docking approach of ClusPro server consists of three successive steps such as rigid body docking, clustering of lowest energy structure, and structural refinement (Kozakov et al. 2017). Based on the lowest energy score and binding efficacy, the best docked complex was selected for dynamics simulation.

2.2.8. Gibbs free energy $(\Delta G)$ and dissociation constant $\left(K_{d}\right)$ calculation: The binding affinity of the protein complex is important in therapeutics development (Kastritis and Bonvin 20I3) because it determines potentiality and strength of a complex to be formed (Xue et al. 2016). Therefore, the Gibbs free energy $(\Delta \mathrm{G})$ of the vaccine-TLR2 complex was predicted with the PRODIGY server (Xue et al. 2016). This web-application works based on pair-wise intermolecular contacts (within $5.5 \AA$ distance threshold) of the binding interface in a protein-protein complex and comparing it with an internal dataset comprising 122 complexes with reliable experimental binding affinities (Vangone and Bonvin 20I5). Based on the predicted $\Delta G$, the dissociation constant $\left(K_{d}\right)$ of the vaccine-receptor complex was 
bioRxiv preprint doi: https://doi.org/10.1101/795146; this version posted October 7, 2019. The copyright holder for this preprint (which was not certified by peer review) is the author/funder, who has granted bioRxiv a license to display the preprint in perpetuity. It is made available under aCC-BY-NC-ND 4.0 International license.

also calculated by $\Delta G=R T \times \mid n K_{d}$ relationship where, $R$ and $T$ are the ideal gas constant and temperature in Kelvin scale, respectively. The PRODIGY server calculates $\Delta G$ by the following equation (Vangone and Bonvin 20I5).

$$
\begin{gathered}
\Delta G=-0.09459 \times\left|C_{\text {charged/charged }}-0.10007 \times\right| C_{\text {charged/apolar }}+0.19577 \times 1 C_{\text {polar/polar }}-0.2267|\times| C_{\text {polar/apolar }}+0.18681 \times \% N I S_{\text {apolar }} \\
+0.3810 \times \% N I S_{\text {charged }}-15.9433
\end{gathered}
$$

Where, $I C_{X Y Y}$ indicates the number of interfacial contacts (IC) found at the interface between chain $A$ and $B$ in terms of the polar, apolar or charged nature of the interacting residues, and \%NIS denotes percentage of the apolar and charged non-interacting surfaces (NIS).

In this study, TLR2 and vaccine molecules were defined as chain $A$ and $B$, respectively and temperature was set to $25^{\circ} \mathrm{C}$ (298K). The TLR2 protein with co-crystallized SSL3 (Staphylococcal superantigen-like protein 3, PDB ID: 5d3i) was used as a positive control.

2.2.9. Molecular dynamics simulation. The study of molecular dynamics is essential for determining the binding stability of a receptor-ligand complex (Pandey, Bhatt, and Prajapati 2018). The molecular dynamics (MD) simulation between TLR2 (as receptor) and vaccine (as ligand) was performed using YASARA Dynamics software v17.8 (Krieger et al. 2004) under AMBERI4 force-field (Dickson et al. 2014). Initially, the complex was cleaned and hydrogen was added to all atoms. The whole procedure was accomplished in a TIP3P-solvated (density: $0.997 \mathrm{~g} / \mathrm{L}^{-1}$ ) simulation cell with default macro setting (md_run.mcr) for 3 nanoseconds until the complex achieved its stable state. A cut-off radius of $8.0 \AA$ was considered at predefined physiological state $(298 \mathrm{~K}, \mathrm{pH} 7.4$, and $0.9 \% \mathrm{NaCl})$. The simulation snapshots were captured at every 100 picoseconds. Finally, the simulation-derived trajectories were analyzed using built-in macros (i.e., md_analyze.mcr and md_analyzeres.mcr) to calculate root mean square deviation (RMSD) and root mean square fluctuation (RMSF), respectively. Besides, the number of hydrogen bonds present in the initial and final YASARA scene was evaluated with BIOVIA Discovery Studio 2017.

2.2.10. Immune simulation studies. The in silico immune response for the vaccine antigen was measured with a dynamic immune simulator embedded in C-ImmSim server (Rapin et al. 2010). This server takes vaccine construct as an input to predict the epitopes and generate real-life-like immune interactions based on position-specific scoring matrix and machine learning techniques, respectively (Rapin et al. 2010). The minimum recommended interval between dose $\mathrm{I}$ and dose 2 for most of the commercial vaccines is 4 weeks (Castiglione et al. 20I2). Therefore, the dosedependent immune response by the vaccine construct was determined using three injections (doses) with four weeks interval period translated into I, 84 and 168 time-steps (I time-step is equivalent to 8 hours in real-life). Furthermore, probable immune response in the pathogen invaded area was calculated using 12 subsequent injections as repeated exposure. In both cases, each dose comprised of 1000 vaccine particles and the simulation was continued for 1050 time-steps ( 350 days). The Simpson index (D) was interpreted as a measure of immune response diversity (Rapin et al. 2010). 
2.2.II. Codon adaptation and in silico cloning. Codon usage in organism differs from species to species, hence, unadapted codon may result in the minor expression rate in the host (Pandey, Bhatt, and Prajapati 2018). Therefore, it should be optimized according to the host translational machinery to improve gene expression (Khatoon, Pandey, and Prajapati 2017). In this study, we used Java Codon Adaptation Tool (JCAT) server (Grote et al. 2005) to adapt our vaccine codon for a widely used prokaryotic model organism, E. coli strain KI2. To avoid the prokaryote ribosome binding site, rho-independent transcription termination, and restriction enzymes cleavage sites, three additional options at the bottom were selected. The codon adaptation index (CAl) value (Sharp and Li 1987) and guanine-cytosine (GC) content of the adapted sequence were calculated. The CAl score is the measure of codon usage biasness and an optimal CAl score should be 1.0 but score greater than 0.8 can be considered as good (Morla, Makhija, and Kumar 2016). An optimal score of GC content range in between 30-70\% (Khatoon, Pandey, and Prajapati 20I7). Then, Xhol and $\mathrm{Ncol}$ restriction sites were introduced to the $\mathrm{N}$ and $\mathrm{C}$-terminal of the optimized nucleotide sequence, respectively. Finally, the adapted deoxyribonucleic acid (DNA) sequence of the designed vaccine was cloned into the multiple cloning site (MCS) of E. coli plasmid pET30a(+) with SnapGene 4.3 tool (https://snapgene.com/) to ensure the expression of desired vaccine protein.

2.2. I2. Data availability. Data not embedded within the manuscript are provided as a supplementary file. The protein sequences used in this study can be retrieved from IMG/M, RCSB PDB and NCBI database using their corresponding accession codes.

\section{Results}

\section{I. Pre-vaccine design analysis}

3.I.I. Selection of PE-PGRS family protein. The proteome of the M. ulcerans Ag99, consisting of 4047 proteins, excluding human homologs, was retrieved from IMG/M system and subjected to antigenicity prediction. Based on the antigenic scores, the top-ten proteins were selected for which the scores were ranged from I.825 to 2.394. All the 10 proteins belonged to the conserved proline-glutamate polymorphic GC-rich sequence (PE-PGRS) family protein of the M. ulcerans. Moreover, no transmembrane helices was found for any of those proteins as shown in Table I. Therefore, we selected the PE-PGRS protein (GenBank: WP_0II740336) with the highest antigenic score (2.394I) that contains 642 amino acid residues.

Table I: The top 10 antigenic proteins resulted in the initial proteome screening

\begin{tabular}{llllll}
\hline SN & $\begin{array}{l}\text { IMG/M } \\
\text { Identifier }\end{array}$ & $\begin{array}{l}\text { Protein } \\
\text { name }\end{array}$ & $\begin{array}{l}\text { Antigenicity } \\
\text { score }\end{array}$ & $\begin{array}{l}\text { Number of TM } \\
\text { helices }\end{array}$ & $\begin{array}{l}\text { Length } \\
\text { (AA) }\end{array}$ \\
\hline I & 642569202 & PE-PGRS family protein & 2.394 & 0 & 642 \\
2 & 642570886 & PE-PGRS family protein & 2.308 & 0 & 929 \\
3 & 642569998 & PE-PGRS family protein & 2.231 & 0 & 667 \\
4 & 642570321 & PE-PGRS family protein & 2.133 & 0 & 558 \\
5 & 642570805 & PE-PGRS family protein & 2.060 & 0 & 728 \\
6 & 642568686 & PE-PGRS family protein & 1.995 & 0 & 461 \\
7 & 642570293 & PE-PGRS family protein & 1.940 & 0 & 458 \\
8 & 642568458 & PE-PGRS family protein & 1.930 & 0 & 403 \\
9 & 642568210 & PE-PGRS family protein & 1.925 & 0 & 789 \\
10 & 642569115 & PE-PGRS family protein & 1.825 & 0 & 636 \\
\hline
\end{tabular}


3.I.2. Evaluation and selection of $T$ and B-cell epitopes. Total 58 unique CTL epitopes (9-mer) were predicted from the M. ulcerans derived PE-PGRS protein in which 24 epitopes have MHC-I binding alleles. The number of alleles for CTL epitopes was ranged from I to 17 (Table SI). After evaluation, 14 epitopes were found as antigenic, immunogenic, non-toxic and had at least 5 MHC-I binding alleles as shown in Table 2. Further, allergenicity assessment showed 5 CTL epitopes were non-allergic, hence, selected for vaccine construction (Table 2). Similarly, a total of II9 unique HTL epitopes (I5-mer) were predicted along with their respective MHC-II binding molecules. Firstly, the HTL epitopes were evaluated based on the number of alleles which resulted in 53 epitopes having a minimum of 5 binding alleles (Table S2). Based on the cytokine inducing ability, I 3 HTL epitopes were found as IFN- $\gamma$ and IL-4 positive in which two epitopes were also IL-10 inducers as provided in Table 3. Finally, 7 epitopes (including 3 overlapping epitopes) were selected based on their antigenic score at 0.5 threshold (Table 3). B-cell epitopes are antigenic regions of a protein that can trigger antibody formation. We found a total of 199 linear B-cell epitopes ( 2 -mer) with probability score 0.502 to 0.843 (Table S3). After evaluation, however, only 6 B-cell epitopes with probability score higher than 0.8 were found to be highly antigenic, non-allergenic and non-toxic as presented in Table 4. Finally, 3 epitopes were selected as unique, therefore, considered for vaccine construction (Table 4).

Table 2: The evaluation and selection of cytotoxic T-lymphocyte (CTL) epitopes

\begin{tabular}{|c|c|c|c|c|c|c|c|c|}
\hline SN & $\begin{array}{l}\text { CTL } \\
\text { Epitopes }\end{array}$ & Position & $\begin{array}{l}\text { Comb } \\
\text { Score }\end{array}$ & $\begin{array}{l}\text { Antigen } \\
\text { Score }\end{array}$ & $\begin{array}{l}\text { Immunogen } \\
\text { Score }\end{array}$ & $\begin{array}{l}\text { Allergen } \\
\text { Property }\end{array}$ & $\begin{array}{l}\text { Toxic } \\
\text { Property } \\
\end{array}$ & Remarks \\
\hline I & AAAVPTTAL & $31-38$ & 1.5339 & 0.5564 & 0.1356 & No & Non-toxin & Selected \\
\hline 2 & AADEVSAAI & $43-51$ & 0.7703 & 0.6396 & 0.0483 & Yes & Non-toxin & Not-selected \\
\hline 3 & AANGAVGSR & $545-553$ & 0.5103 & 2.1085 & 0.0409 & No & Non-toxin & Selected \\
\hline 4 & ALAAGGASY & $78-77$ & 1.5616 & 0.8068 & 0.05333 & Yes & Non-toxin & Not-selected \\
\hline 5 & APNGGAGGL & $127-136$ & $1.408 \mid$ & 1.8634 & 0.15023 & Yes & Non-toxin & Not-selected \\
\hline 6 & DEVSAAIAA & $45-53$ & 0.519 & 0.5864 & 0.05704 & Yes & Non-toxin & Not-selected \\
\hline 7 & EVSAAIAAL & $46-54$ & 1.3825 & 0.575 & 0.20493 & Yes & Non-toxin & Not-selected \\
\hline 8 & GGDGGHGAY & $453-461$ & 0.7632 & 2.6448 & 0.15621 & No & Non-toxin & Selected \\
\hline 9 & GQGGGAGTL & $205-213$ & 1.0216 & 3.2446 & 0.16621 & Yes & Non-toxin & Not-selected \\
\hline 10 & LWPAAADEV & $39-47$ & 0.5785 & 0.9216 & 0.18792 & Yes & Non-toxin & Not-selected \\
\hline II & LYGNGGNGY & $147-155$ & $0.747 \mid$ & 2.0088 & 0.08373 & Yes & Non-toxin & Not-selected \\
\hline 12 & SSDAANGAV & $542-550$ & 2.1709 & 1.3153 & 0.13004 & Yes & Non-toxin & Not-selected \\
\hline 13 & VSAAIAALF & $47-55$ & 1.7464 & 0.6021 & 0.24504 & No & Non-toxin & Selected \\
\hline 14 & YLSVAPDEL & $3-11$ & 1.2856 & 1.0078 & 0.09272 & No & Non-toxin & Selected \\
\hline
\end{tabular}

Table 3: The evaluation and selection of helper T-lymphocyte (HTL) epitopes

\begin{tabular}{llllllll}
\hline SN & HTL Epitopes & Position & Antigenicity & IFN- $\boldsymbol{I L}$ & IL-4 & IL-I0 & Remarks \\
\hline I & AYHDQFVRALAAGGA & $71-85$ & 0.4246 & Positive & IL4 inducer & ILI0 negative & Not-selected \\
2 & GGGGSQVGSDGVGGA & $380-394$ & 3.3983 & Positive & IL4 inducer & ILI0 negative & Selected \\
3 & GSIVSTVNAAAAVPT & $22-36$ & 0.3182 & Positive & IL4 inducer & ILI0 negative & Not-selected \\
4 & GVGSIVSTVNAAAAV & $20-34$ & 0.4816 & Positive & IL4 inducer & ILI0 negative & Not-selected \\
5 & HAQQYQSLSVQVAAY & $58-72$ & 0.8065 & Positive & IL4 inducer & ILI0 inducer & Selected \\
6 & LSVAPDELAAAATEL & $4-18$ & 0.7293 & Positive & IL4 inducer & ILI0 negative & Selected \\
7 & RGVGSIVSTVNAAAA & I9-33 & 0.4037 & Positive & IL4 inducer & ILI0 negative & Not-selected \\
8 & SHAQQYQSLSVQVAA & $57-71$ & 0.8395 & Positive & IL4 inducer & ILI0 inducer & Selected \\
9 & SIVSTVNAAAAVPTT & $23-37$ & 0.2693 & Positive & IL4 inducer & ILI0 negative & Not-selected \\
I0 & SVAPDELAAAATELR & $5-19$ & 0.8928 & Positive & IL4 inducer & ILI0 negative & Selected \\
II & VAPDELAAAATELRG & $6-20$ & 0.8569 & Positive & IL4 inducer & ILI0 negative & Selected \\
I2 & VGSIVSTVNAAAAVP & $21-35$ & 0.1564 & Positive & IL4 inducer & ILI0 negative & Not-selected \\
I3 & YHDQFVRALAAGGAS & $72-86$ & 0.5786 & Positive & IL4 inducer & ILI0 negative & Selected \\
\hline
\end{tabular}


Table 4: The evaluation and selection of linear B-lymphocyte (LBL) epitopes

\begin{tabular}{llllllll}
\hline SN & LBL Epitopes & Probability & Position & Antigenicity & Allergenicity & Toxicity & Remarks \\
\hline I & GNGGRGGDGIRG & 0.8431 & $344-355$ & 3.7111 & No & No & Not-selected \\
2 & GGNGGRGGDGIR & 0.8392 & $343-354$ & 4.0397 & No & No & Selected \\
3 & LLYGNGGNGYDN & 0.8293 & $136-147$ & 1.0946 & No & No & Not-selected \\
4 & GNGGNGYNSAS & 0.8095 & $139-150$ & 2.087 & No & No & Selected \\
5 & GAGGAGGTGGAG & 0.8285 & $393-404$ & 4.2749 & No & No & Selected \\
6 & GGAGGAGGTGGA & 0.8285 & $392-403$ & 4.1151 & No & No & Not-selected \\
\hline
\end{tabular}

3. I.3. Molecular docking between epitopes and HLA alleles. The epitopes selected for vaccine construction are meant to have a good affinity towards their HLA binding alleles. In this study, the binding affinity of the CTL epitopes and control was ranged within -6.3 to -9.2 and -6.7 to -9.6 , respectively as given in Table 5. For HTL epitopes, the binding affinity was determined in between -6.2 to -7.8 for epitopes while control provided -5.5 to $-7.8 \mathrm{kcal} / \mathrm{mole}$ (Table 5). Therefore, 2 CTL and 4 HTL epitopes showed better binding affinity towards their respective HLA alleles as compare to control ligands. The rest of the epitopes showed binding affinity relatively close to the control ligands. The amino acid residues involved in the hydrogen bond interactions were also analyzed and included in Table 5. Here, Fig. 2 shows the best CTL (YLSVAPDEL) and HTL (YHDQFVRALAAGGAS) epitopes in terms of docking score and rest are shown in Fig. SI.

Table 5: The efficacy of the selected CTL \& HTL epitopes to be used in vaccine construction

\begin{tabular}{|c|c|c|c|c|c|}
\hline \multirow{2}{*}{\multicolumn{2}{|c|}{$\begin{array}{l}\text { Selected } \\
\text { Epitopes }\end{array}$}} & \multirow{2}{*}{$\begin{array}{l}\text { HLA binding } \\
\text { allele }\end{array}$} & \multicolumn{2}{|c|}{ Binding affinity } & \multirow{2}{*}{$\begin{array}{l}\text { Residues involved in hydrogen } \\
\text { bond interactions }\left(\mathrm{N}_{\mathrm{CBH}}\right)\end{array}$} \\
\hline & & & Epitope & Control & \\
\hline \multirow{4}{*}{$\stackrel{n}{\vec{E}}$} & AAAVPTTAL & & -8.8 & -9.6 & $\begin{array}{l}\text { Arg62, Lys I46, Trpl47, ArgI56, Ala3, Leu9, } \\
\text { Val4, Thr6 }(\mathrm{N}=7)\end{array}$ \\
\hline & AANGAVGSR & HLA-A*II0I & -7.2 & -6.8 & $\begin{array}{l}\text { Gln70,Argl I4, Trp|47, Tyr|59, Ala5, Val6, } \\
\text { Gly7, Arg9 }(N=8)\end{array}$ \\
\hline & VSAAIAALF & HLA A*0I0I & -6.4 & -6.7 & $\begin{array}{l}\text { Thr73, Asn77, ArgI I4, Arg163, Ser2, Tyr99, } \\
\text { Vall, Ala4, Phe9, Leu8 }(\mathrm{N}=6)\end{array}$ \\
\hline & YLSVAPDEL & HLA-B*390I & -9.2 & -8.2 & $\begin{array}{l}\text { Lys I46, Arg62, Ser77, Asn80, Trp I47, Leu9, } \\
\text { Tyrl, Asp7, Glu8, Thrl 43, Tyr84 (N=9) }\end{array}$ \\
\hline \multirow{8}{*}{$\stackrel{y}{\underline{E}}$} & GGDGGHGAY & HLA A*0I0I & -6.3 & -6.7 & Arg156, Tyr9, Gly7 (N=2 \\
\hline & GGGGSQVGSDGVGGA & DRBI*IIOI & -6.7 & -5.5 & $\begin{array}{l}\text { Gln9, Glu55, Asn62, Ser II, Tyr30, Arg7I, } \\
\text { His8I, Gly3, Gly4, Ser5, Gly13, Val7, Gly|4, } \\
\text { Gly15, ValI2, Ala I5, Gln6, Asn82, Thr77 } \\
(\mathrm{N}=\mathrm{II})\end{array}$ \\
\hline & HAQQYQSLSVQVAAY & DRBI*IIOI & -6.2 & -5.5 & $\begin{array}{l}\text { Gln9, Ser53, Asn62, Asn69, Arg7I, Thr77, } \\
\text { Asn82, Tyr5, Ser9, His I, Leu8, Ala2, Gln3, } \\
\text { Tyr15 (N=9) }\end{array}$ \\
\hline & LSVAPDELAAAATEL & DQAI*030I & -6.6 & -7.8 & $\begin{array}{l}\text { Asp55, Asn62, Asn69, Arg70, Arg77, Asn82, } \\
\text { Ala 12, Leu8, Leu I, Pro5, Ala4, Ala9, Glu 14, } \\
\text { Leu 15, Ala I0 ( } \mathrm{N}=\text { II) }\end{array}$ \\
\hline & SHAQQYQSLSVQVAA & DRBI*IIOI & -6.5 & -5.5 & $\begin{array}{l}\text { Gln9, Asn62, Ser13, Arg7I, Thr77, His8I, } \\
\text { Ser88, Ala I5, Ser8, Tyr6, Gln7, Gln5, SerI, } \\
\text { Gln 12, Gly84 }(N=10)\end{array}$ \\
\hline & SVAPDELAAAATELR & DQAI*030I & -7.4 & -7.8 & $\begin{array}{l}\text { Tyr22, Asp55, Phe58, Trp61, Arg70, Lys7I, } \\
\text { Arg77, Asn82, Ala 10, Thr I2, Leul4, Argl I, } \\
\text { Val2, Glu6, Glu 13, Asn62, Ser28, Ala3 (N=13) }\end{array}$ \\
\hline & VAPDELAAAATELRG & DQAI*030I & -6.6 & -7.8 & $\begin{array}{l}\text { His24, Asn62, Asn69, Arg70, Asn82, Gly15, } \\
\text { Vall, Asp4, Glu5, Ala2, Tyr9, Argl4 (N=8) }\end{array}$ \\
\hline & YHDQFVRALAAGGAS & DRBI*0I0I & -7.8 & -5.6 & $\begin{array}{l}\text { Glu55, Asn62, Arg7I, Thr77, His8I, Asn82, } \\
\text { TyrI, Ala8, Asp3, His2, Gln4, Phe5, Gly12, } \\
\text { Gln70 (N=I0) }\end{array}$ \\
\hline
\end{tabular}


The best CTL epitope 'YLSVAPDEL' formed 9 hydrogen bonds with II active site residues (Table 5) while respective control provided 8 hydrogen bonds which involved amino acid residues Ser77, Asn80, Arg97, Lys I46, Trp I47, Gln I55, His2, Asn7, Leu9, Ala4, Ala8, Glu6, and Thrl63 of active site. On the other hand, best HTL epitope 'YHDQFVRALAAGGAS' was involved with 14 residues (Table 5) through 10 hydrogen bond interactions while control ligand interacted with residues Glu55, His8I, Asn82, Ser3, TyrI I, Gln 13, Asp4, Arg9, Ser53, Thr77 to form 6 hydrogen bonds. In conclusion, all tested epitopes showed good binding affinity towards the respective HLA alleles. Therefore, the selected epitopes were considered as the most potential epitopes to be used in multi-epitope based vaccine design.

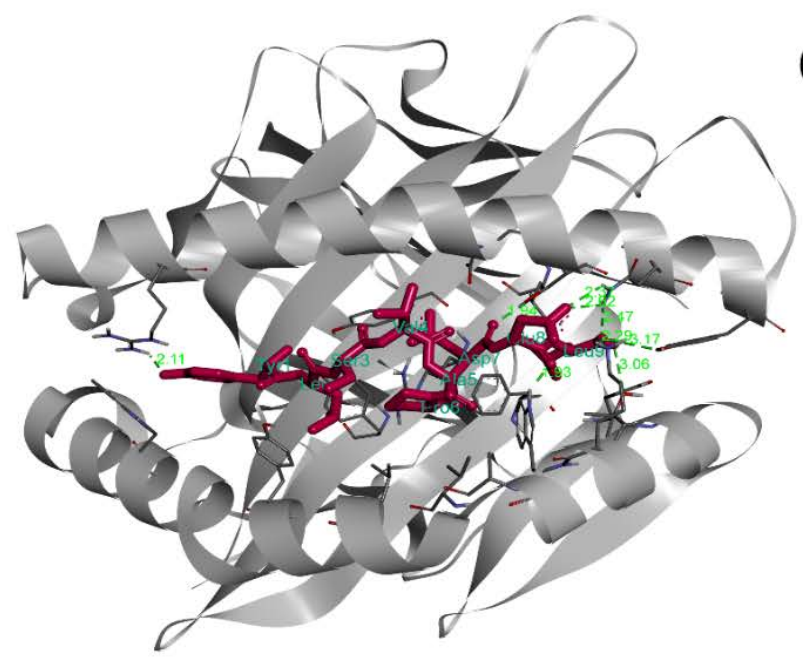

\section{HLA-B*3901-Cocrystal Ligand}

Complex

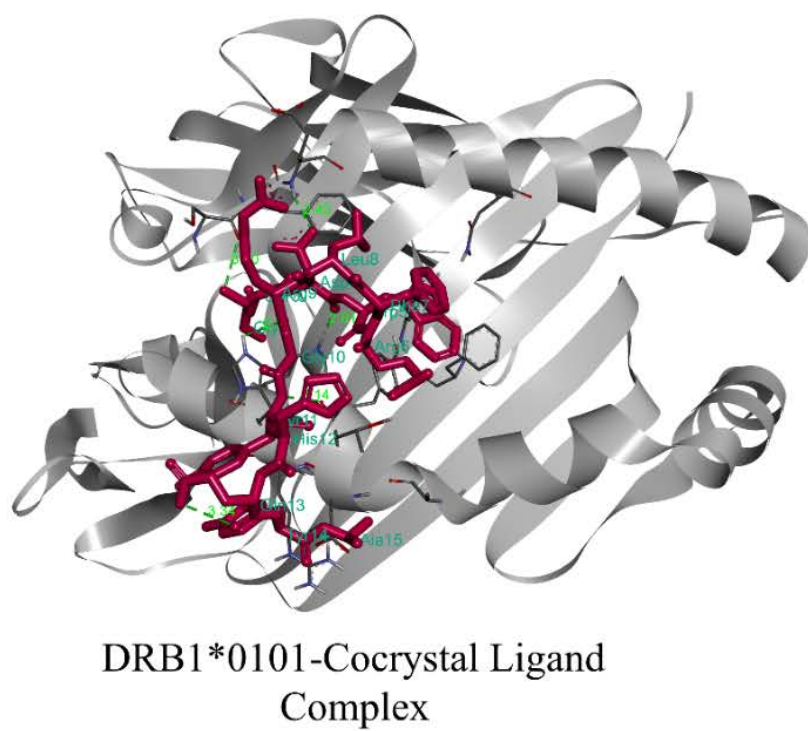

(a)

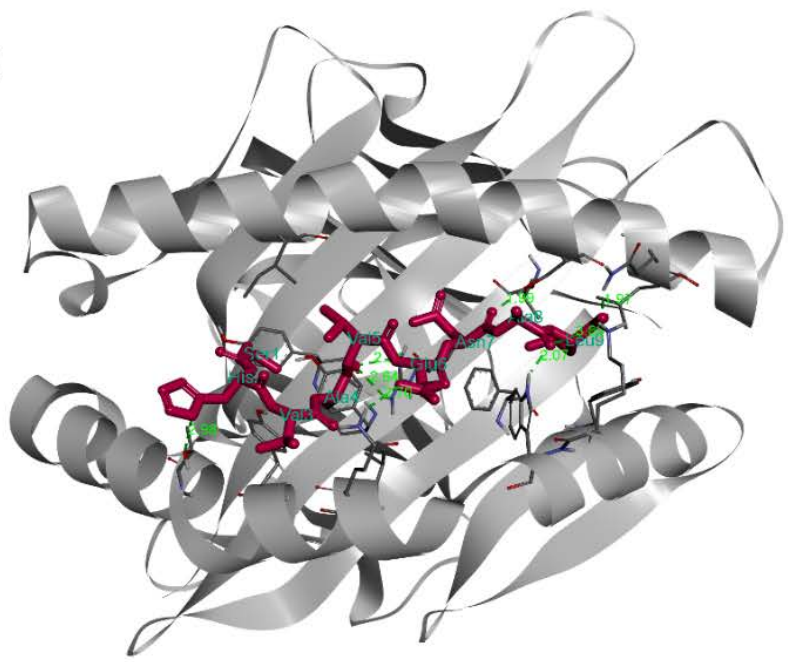

HLA-B*3901-YLSVAPDEL

Complex

(b)

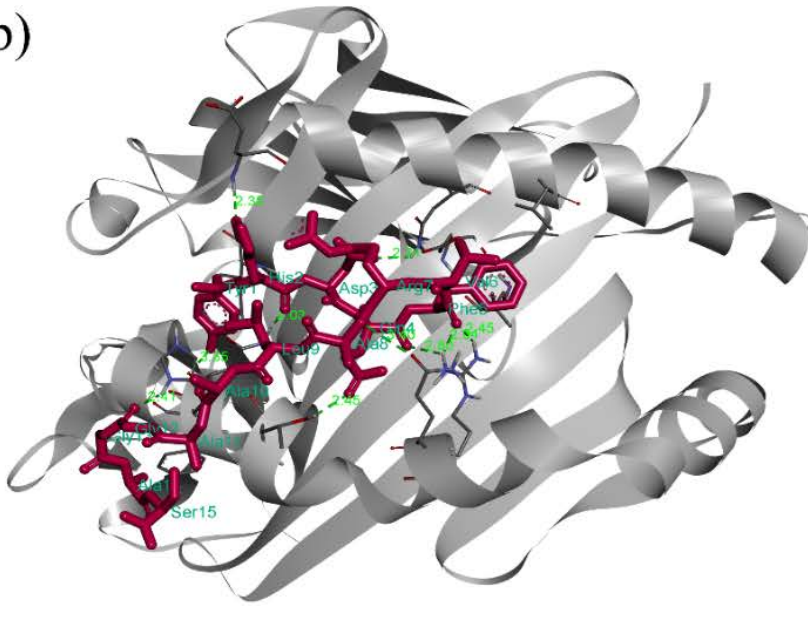

DRB1*0101-YHDQFVRALAAGGAS

Complex

Fig. 2: Molecular docking between T-cell epitopes and their respective HLA binding alleles (a) docking of HLA-B*390I allele with the co-crystal ligand (left) and the best CTL epitope (YLSVAPDEL) (right) where residue Lys 146, Arg62, Ser77, Asn80, Trp147, Leu9, TyrI, Asp7, Glu8, ThrI43, and Tyr84 were involved forming total nine conventional hydrogen bonds, (b) docking of $\mathrm{DRBI} * 0 \mathrm{I} 0 \mathrm{I}$ with the co-crystal ligand (left) and the best $\mathrm{HTL}$ epitope (YHDQFVRALAAGGAS) (right) where residue Glu55, Asn62, Arg7I, Thr77, His8I, Asn82, Tyrl, Ala8, Asp3, His2, Gln4, Phe5, Gly12, and Gln70 took part to provide ten conventional hydrogen bonds. 
3. I.4. World population coverage: The population coverage was estimated with finally selected $5 \mathrm{CTL}$ and $7 \mathrm{HTL}$ epitopes and corresponding HLA alleles. Our selected CTL and HTL epitopes showed $99.55 \%$ and $56.36 \%$ of global population coverage, respectively (Table S4). Since vaccine will contain both types of epitopes, we emphasized on their combined coverage which was $99.8 \%$ of world population as shown in Fig. 3. The highest coverage (100\%) was found within the population from two countries such as Bulgaria (other ethnic group) and Peru (Fig. 3). In Uganda, where $M$. ulcerans was first identified, the population coverage was $96.9 \%$ (Fig. 3b). Also, the population coverage was higher in regions where Buruli ulcer occurrence have been reported such as West Africa (98.59\%), Central Africa (97.13\%), South America (99.63\%), and Western Pacific regions i.e., Australia (96.67\%), Japan (99.74\%), New Zealand (47.99\%), and Singapore (96.55\%) (Fig. 3 and Table S4). The population coverage for South Asia, India and Europe were $99.75 \%$, $99.63 \%$ and $99.84 \%$, respectively. However, the least population coverage $(0 \%)$ was predicted for the European country Slovakia (Table S4), which is plausible due to the lower allele frequency based on the data available in Allele Frequencies (http://allelefrequencies.net) database.

(a)

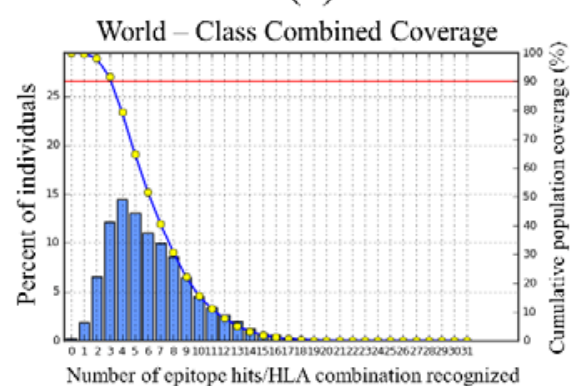

(d)

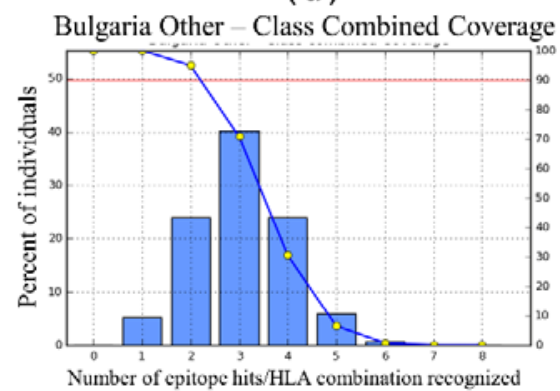

(g)

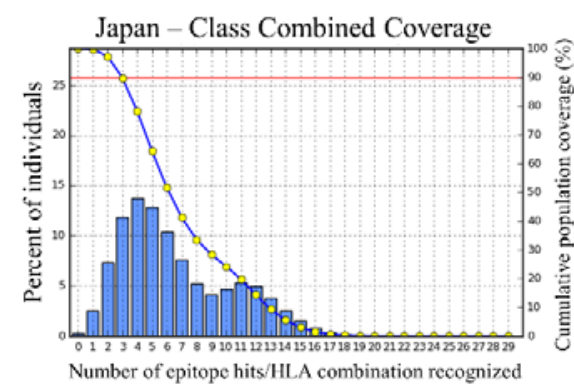

(b)

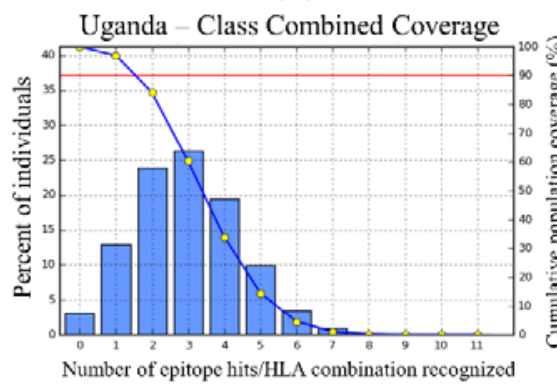

(e)

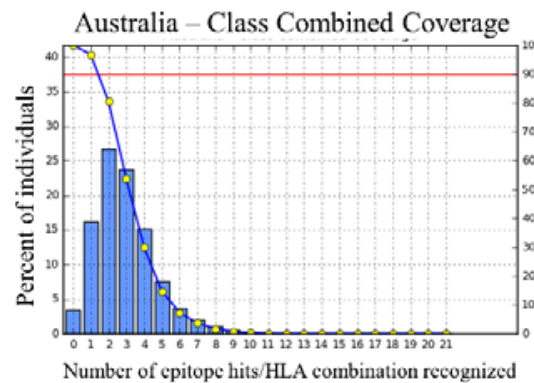

(h)

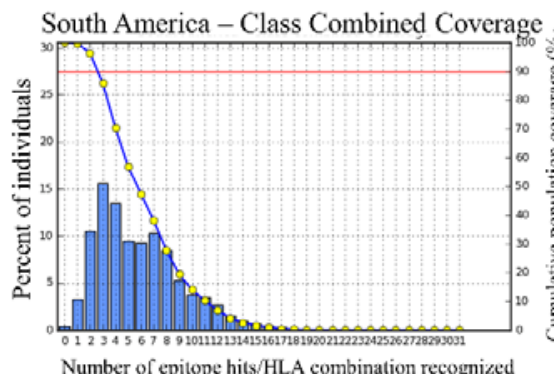

(c)

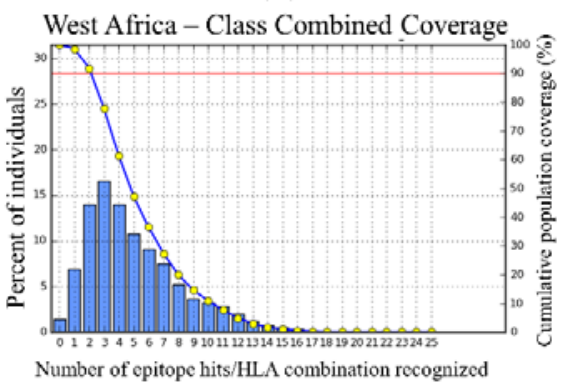

(f)

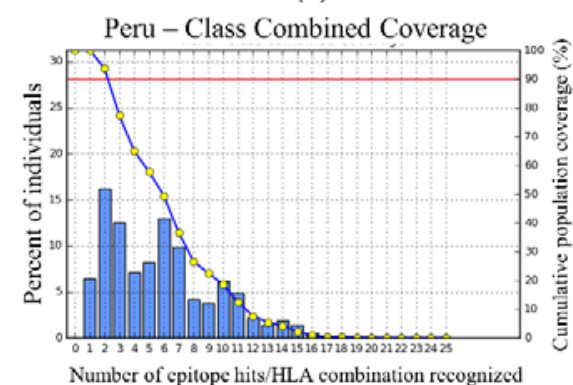

(i)

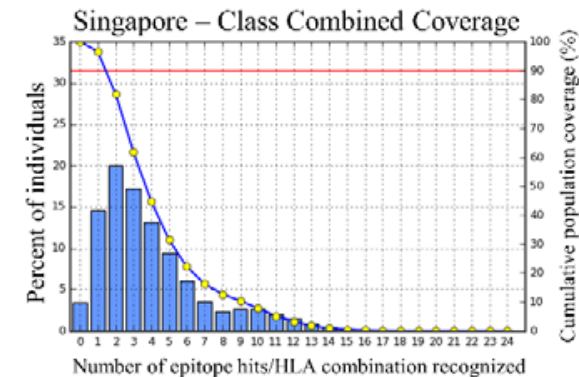

Fig. 3: Worldwide population coverage by T-cell epitopes based on their respective HLA binding alleles. Regions of particular interest were considered here: (a) World, 99.80\%; (b) Uganda, 96.90\%; (c) West Africa, 98.59\% (d) Bulgaria other, 100\%; (e) Australia, 96.67\%; (f) Peru, 100\%; (g) Japan, 99.74\%; (h) South America, 99.63\%; (i) Singapore, $96.55 \%$ coverage. 


\subsection{Vaccine design and post-vaccine studies}

3.2.I. Construction of multi-epitope vaccine: $A$ total of 15 epitopes were arranged in an aforementioned way to construct the chimeric vaccine protein. The selected $7 \mathrm{HTL}, 5 \mathrm{CTL}$ and 3 LBL epitopes were merged with GPGPG, $A A Y$, and KK linkers, respectively. The vaccine construct contains epitopes in order of HTL, CTL and LBL in which epitopes in each group were mapped according to their higher to lower antigenic score. Furthermore, TLR2 agonist LprG protein (236 residues) was added as an adjuvant to the first HTL epitope using EAAAK linkers. The arrangement of different epitopes along with their joining linkers is shown in Fig 4 . The final vaccine construct comprises 520 amino acid residues.

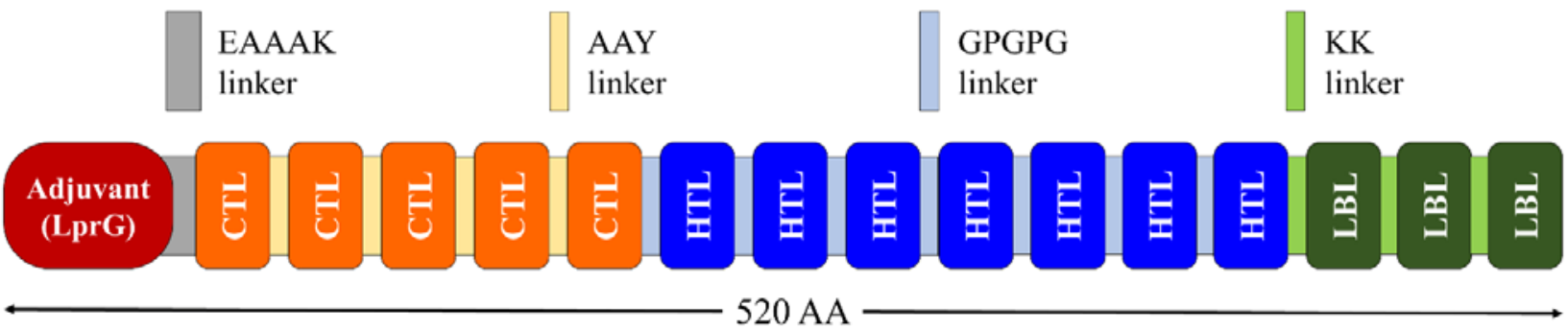

Fig. 4: The organization of $T$ and B-cell epitopes in multi-epitope vaccine construct. Finally constructed protein chimera was 520 amino acid residues long in which first $24 I$ residues have been represented as adjuvant $(M$. ulcerans IprG protein) attached to EAAAK linker $\left(A A_{1}-A A_{241}\right)$ followed by seven HTL epitopes with GPGPG linkers $\left(A A_{242}-A A_{376}\right)$, five $C T L$ epitopes with $A A Y$ linkers $\left(A A_{377}-A A_{436}\right)$, and three $L B L$ epitopes with $K K$ linkers $\left(A A_{437-}\right.$ $\left.\mathrm{AA}_{520}\right)$.

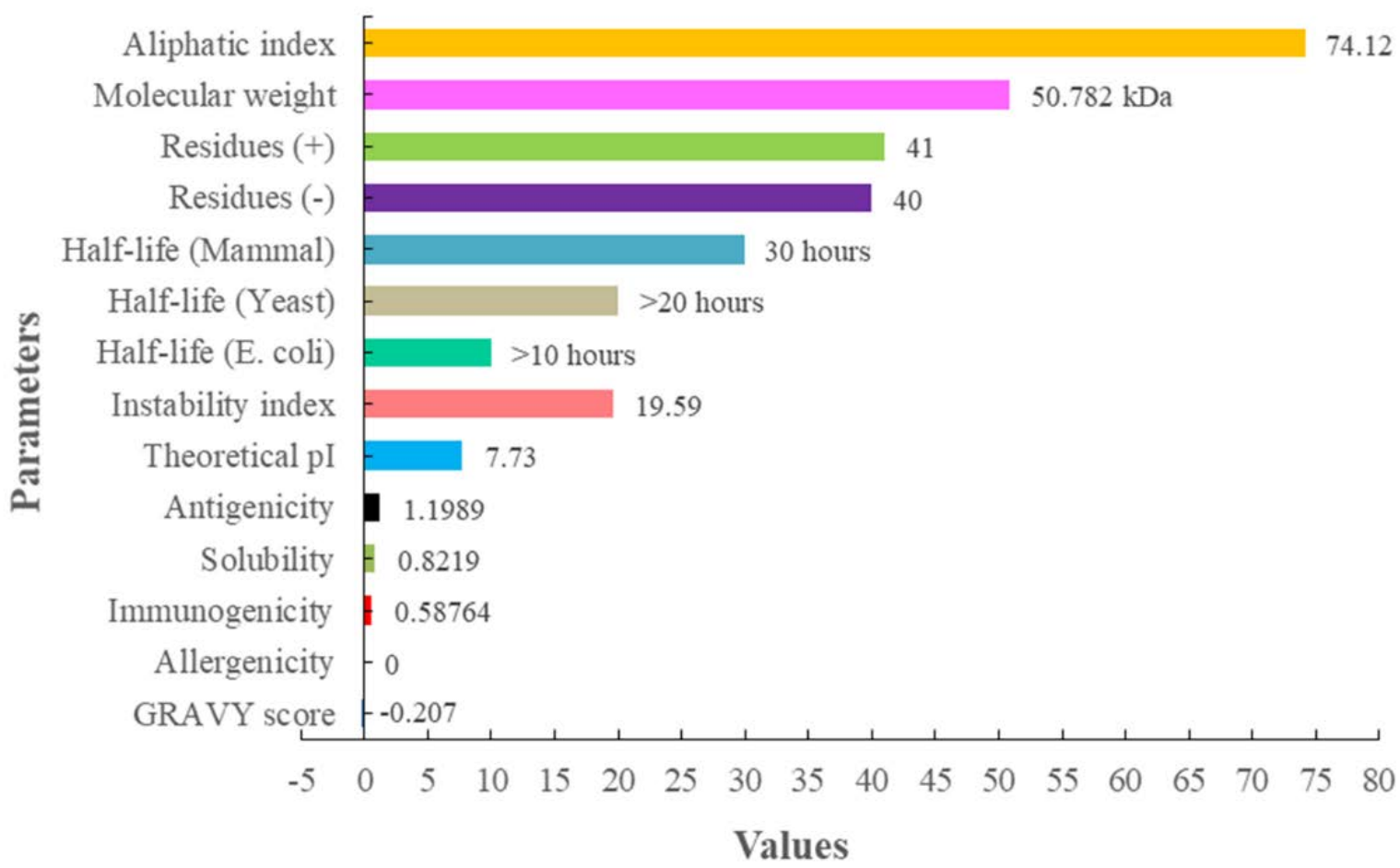

Fig. 5: Physicochemical and immunogenic profile of the designed vaccine protein. The vaccine construct is $50.78 \mathrm{kDa}$ in size, slightly basic (theoretical PI above 7.0), hydrophilic (negative GRAVY value), stable (II below 40 ), thermostable (higher Al value), antigenic (0.5 threshold), immunogenic (positive score), non-allergenic (null), and highly soluble $(\approx 1.0)$ upon overexpression within $E$. coli system. 
3.2.2. Physicochemical and immunogenic profiles. The evaluated physicochemical and immunogenic properties of vaccine construct are shown in Fig. 5. The construct was found to be slightly basic (theoretical PI > 7), stable (Instability Index $<40$ ), and hydrophilic (negative GRAVY value) in nature. The aliphatic index (Al) contributes to the protein's thermal stability and protein with higher Al score are more thermostable (Panda and Chandra 20I2). Therefore, the construct could be thermostable (Al value of 74.12) and it may also contain high amount of hydrophobic amino acids. Moreover, both SolPro and Protein-Sol servers predicted the construct as highly soluble $(\approx 1.0)$ during overexpression in E. coli system (Fig. 5 and 7b). Besides, the half-life was estimated to be about 30 hours in mammalian reticulocytes (in vitro), more than 20 hours in yeast (in vivo) and over 10 hours in E. coli (in vivo). Furthermore, the immunogenic assessment also revealed that the vaccine construct is highly antigenic ( 0.5 threshold), immunogenic (positive value) and non-allergenic (Fig. 5). These results indicated that the designed chimeric construct is suitable to be a potential vaccine candidate.

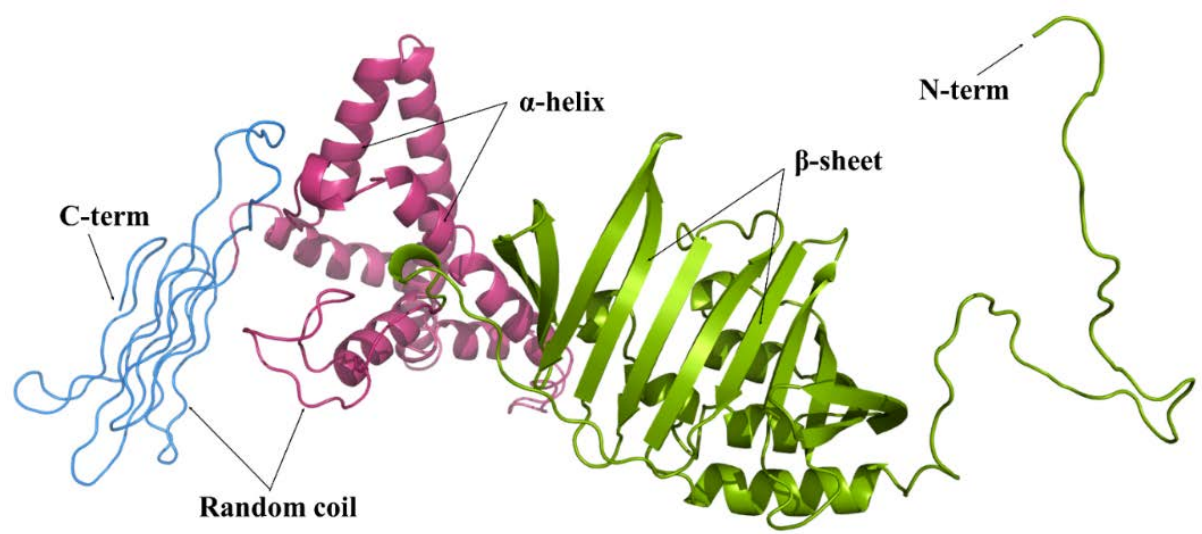

Fig. 6: The three-dimensional structure of the vaccine construct. The figure shows predicted domain-I $\left(A A_{\text {I. }}\right.$ $241)$, domain-2 ( $\left.\mathrm{AA}_{242-420}\right)$, and domain-3 $\left(\mathrm{AA}_{421-520}\right)$ of the vaccine protein in green, pink and blue color, respectively.

3.2.3. Secondary and tertiary structures. The secondary structural analysis demonstrated the presence of $34.23 \%$ $\alpha$-helix (178), 17.31\% $\beta$-sheet (90) and 48.46\% random coil (252) structure in the formulated vaccine construct (Fig. 7a). Furthermore, homology modelling of vaccine protein was performed using the RaptorX server. A total of 520 amino acid residues was modelled as three-domains (Fig. 6). The RaptorX server uses multi-template based approach to build a protein model. For example, the template PDB ID: 3mh9_A and 3mh8_A were chosen to model domain I (I-24I residues, $p$-value: I.43e-09). Similarly, for domain 2 (242-420 residues, $p$-value: I.67e-04) PDB ID: 2a65_A, 4us3_A, and 5i6x_A; and domain 3 (42I-520 residues, $p$-value: I.43e-07) PDB ID: 6f45_D were considered (Table S7). The $p$-value is a quality indicator in homology modelling where $p$-value lower than $10^{\wedge}-3$ defines higher model quality. Since we found very small and significant $p$-value, the chimeric protein was considered to be of good quality.

Table 6: The evaluation of the crude and refined vaccine model for validation

\begin{tabular}{llll}
\hline Parameters & Crude Model & Refined Model & Remarks \\
\hline Rama favored (AA) & $94.2 \%(488)$ & $95.8 \%(496)$ & Favored residues increased \\
Model quality (Z-score) & -6.47 & -7.14 & More like crystal structure \\
Quality factor (ERRAT) & 76.533 & 86.836 & Quality improvement \\
& Errors: 4 & Errors: 3 & Less errors \\
PROCHECK & Warning: 2 & Warning: 3 & Pass: 2 \\
& Pass: 3 & & \\
\hline
\end{tabular}


3.2.4. Tertiary structure refinement and validation. Structure refinement with GalaxyRefine leads to an increased number of residues in the favored region. Of all the refined models, the model 2 proved to be the best based on various parameters including GDT-HA (0.9558), RMSD (0.4I3), MolProbity (1.974), Clash score (14.0), Poor rotamers (0.6) and Rama favored (95.4) as shown in Table S8. This model was taken as the final vaccine model and subjected to structural validation along with the crude model. The quality score (e.g., Z-score) of the refined model was found to be -7.14 as compared to -6.47 of crude model which indicated that the quality was improved as presented in Table 6 and Fig. 7c. In Ramachandran plot, 95.8\% (496) residues were found in the favored region with 3.7\% (19) and 0.6\% (3) residues in allowed region and outlier region, respectively (Fig. 7d). On the other hand, crude model showed $94.2 \%$ (488) residues in the favored region (Table 6). The overall quality factor (ERRAT score) of the crude model was 76.53 which was increased to 86.84 in the refined vaccine model. Furthermore, the refined model showed 3 errors in PROCHECK operation while crude structure had 4 errors. These results suggest that the quality of the refined model is better than the crude model.

(a)

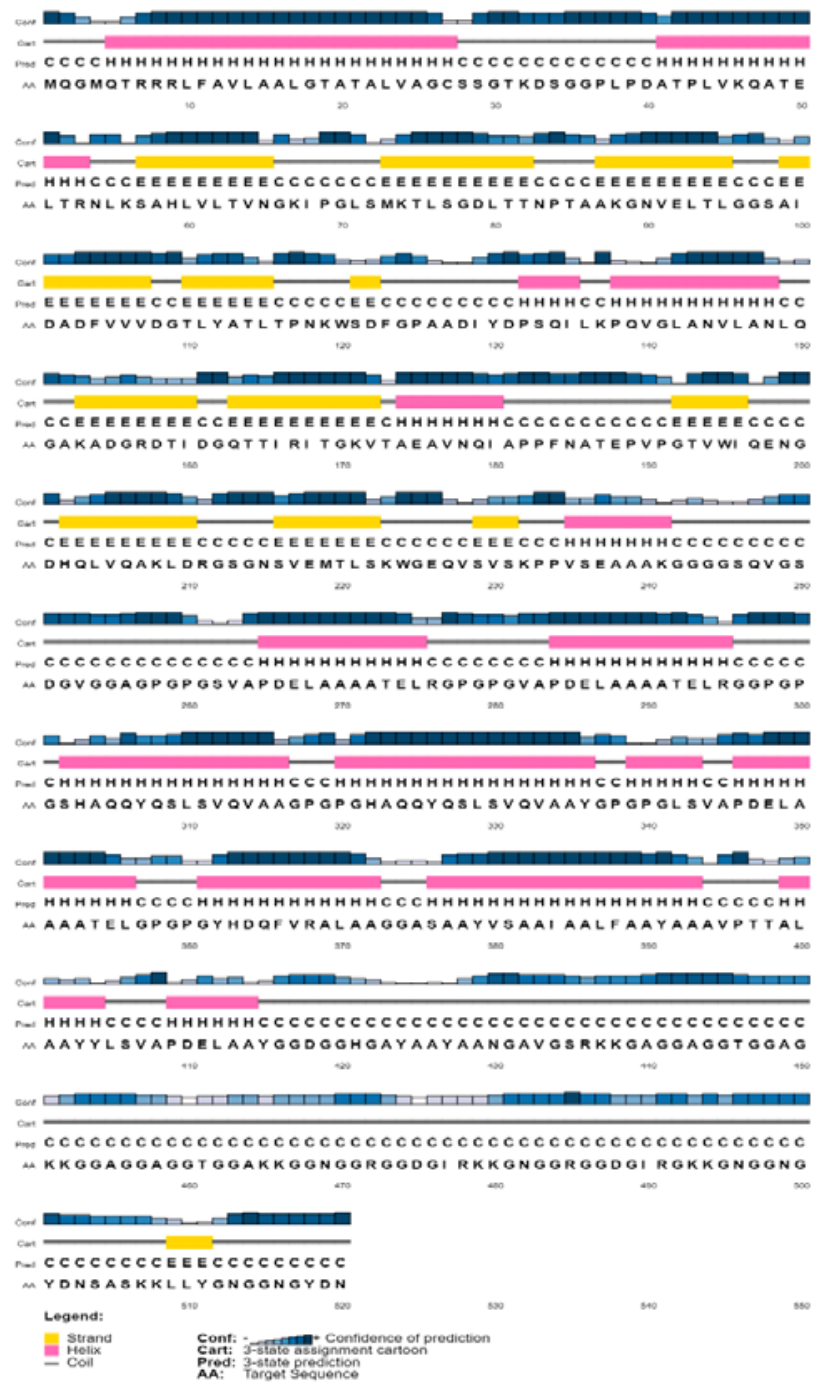

1.0 Solubility

(b)

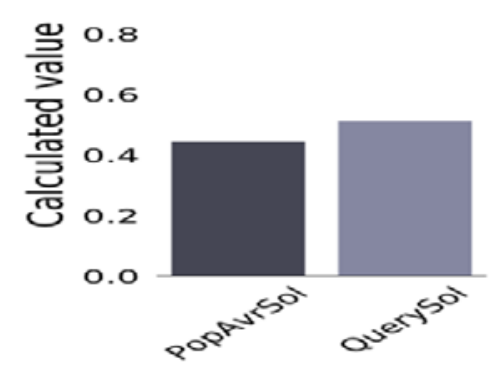

(c)

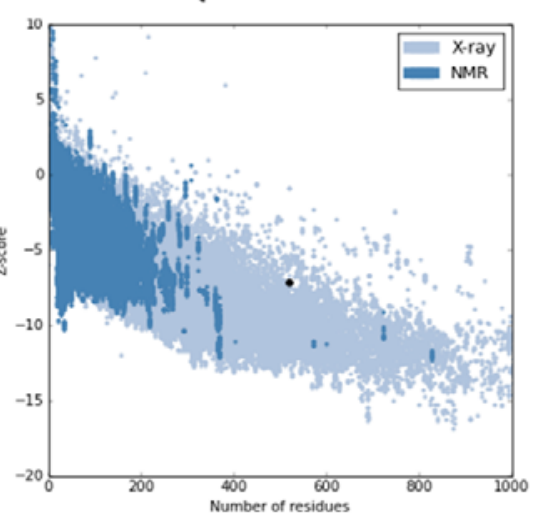

(d)

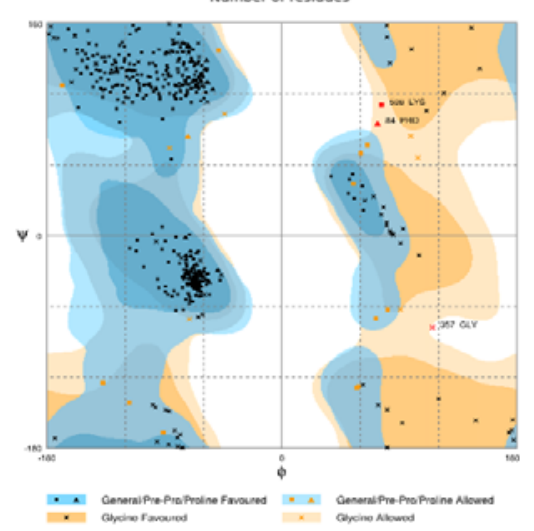

Fig. 7: The secondary structural features and assessment of the tertiary structure (a) the vaccine construct contains $\alpha$-helix $(34.23 \%, 178), \beta$-strand $(17.31 \%, 90)$ and random coil $(48.46 \%, 252)$; (b) the solubility of the vaccine protein is higher than average protein as suggested by Protein-Sol server, (c) the Z-score (-7.14) of the vaccine model 
indicates quality closer to X-ray crystal protein structure and refined positively; and (d) the Ramachandran plot of refined structure shows $95.8 \%, 3.7 \%$ and $0.6 \%$ residues in favored, allowed and disallowed region, respectively.

3.2.5. Discontinuous B-cell epitopes. A total of 12 conformational B-cell epitopes were identified in the vaccine protein as presented in Fig. 8 . The size of the epitopes was fall in between 3 to 98 residues while the numbers of total amino acids were 263 residues as provided in Table S9. Further, the scores of the conformational B-cell epitopes ranged from $0.5 \mathrm{I}$ to 0.99 .

(a)

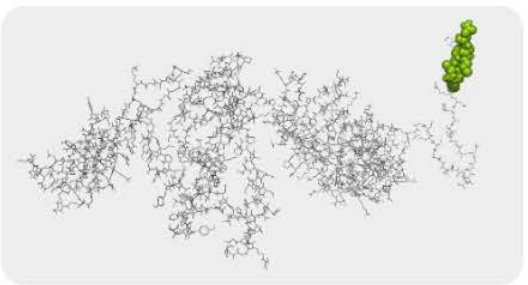

(d)

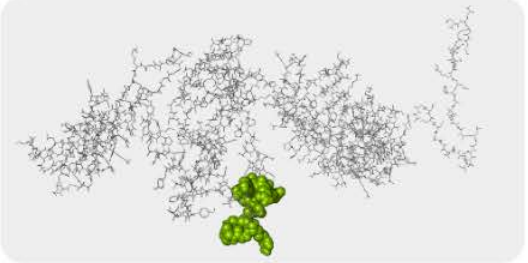

$(\mathrm{g})$

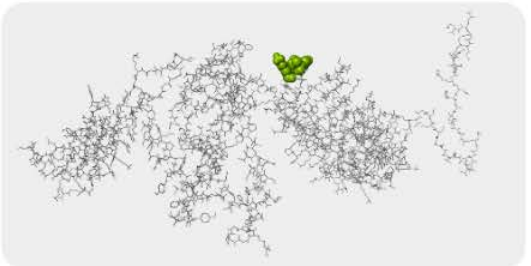

(j)

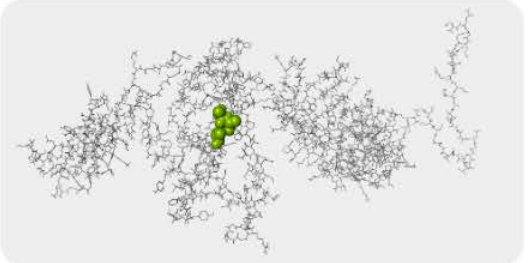

(b)

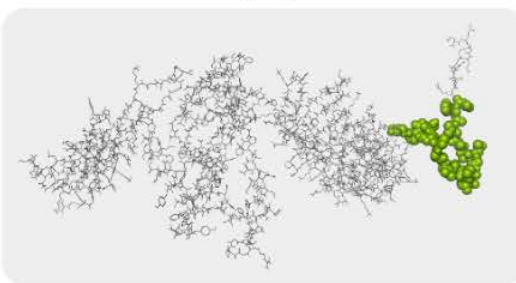

(e)

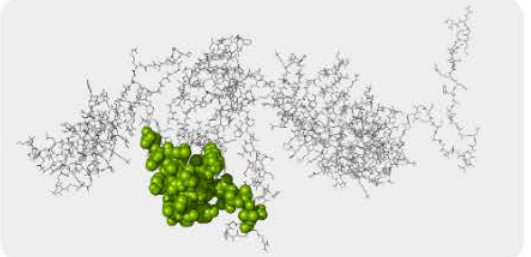

(h)

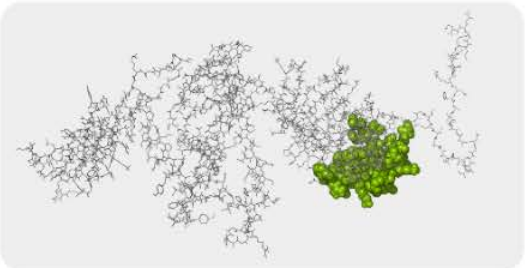

(k)

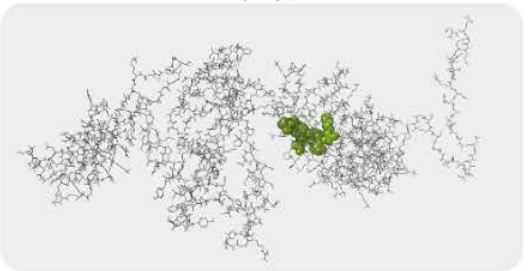

(c)

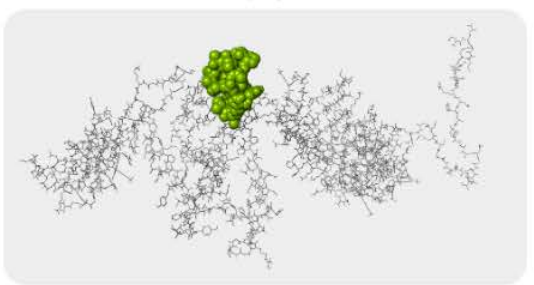

(f)

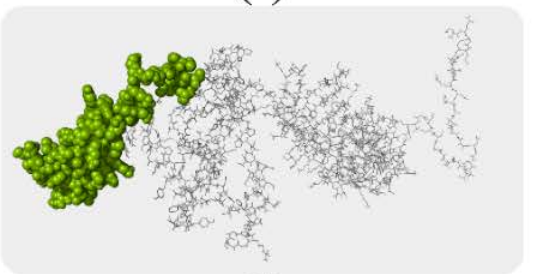

(i)

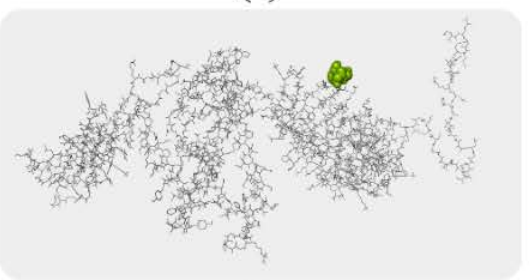

(1)

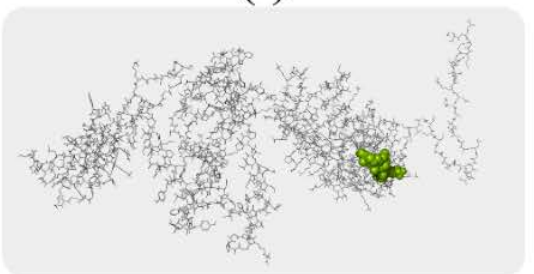

Fig. 8: The conformational B-lymphocyte epitopes present in the vaccine. The light green spheres showing epitopes containing (a) 7 residues $\left(\mathrm{AA}_{2-8}\right)$ with 0.99; (b) 23 residues $\left(\mathrm{AA}_{10-32}\right)$ with 0.87 ; (c) 18 residues $\left(\mathrm{AA}_{350-365}\right.$ and $\left.\mathrm{AA}_{367-368}\right)$ with 0.8I; (d) 13 residues $\left(\mathrm{AA}_{295-307}\right)$ with 0.79; (e) 38 residues $\left(\mathrm{AA}_{283}, \mathrm{AA}_{286-294}, \mathrm{AA}_{379}, \mathrm{AA}_{382-407}\right.$, and $\left.A \mathrm{~A}_{410}\right)$ with 0.78; (f) 98 residues $\left(\mathrm{AA}_{339}, \mathrm{AA}_{343}, \mathrm{AA}_{347}, \mathrm{AA}_{417-419}, \mathrm{AA}_{423-434}, \mathrm{AA}_{438}, \mathrm{AA}_{441-477}, \mathrm{AA}_{479-520}\right)$ with 0.69; (g) 4 residues $\left(A A_{116-119}\right)$ with 0.67; (h) 43 residues $\left(A_{33-47}, A_{49-51}, A_{53-54}, A_{138}, A A_{150-157}, A A_{159}, A_{161-164}, A_{166}, A_{169}\right.$, and $A_{197 .}$ 203) with 0.66; (i) 4 residues $\left(A A_{96-99}\right)$ with 0.64; (j) 3 residues $\left(A A_{371-372}\right.$, and $\left.A A_{375}\right)$ with 0.53; $(k) 7$ residues $\left(A_{223}\right.$, $\left.\mathrm{AA}_{225-230}\right)$ with 0.52; and (I) 5 residues $\left(\mathrm{AA}_{171}, \mathrm{AA}_{186-189}\right)$ with $0.5 \mathrm{I}$ scores.

3.2.6. Vaccine stability improvement. A total of 58 pairs of residues were identified that are suitable for disulfide engineering (Table SI0). After evaluating energy score and $\chi 3$ angle, only four pair of residues were finalized because their value satisfies the defined criteria i.e., energy score should be less than $2.2 \mathrm{kcal} / \mathrm{mol}$ and $\chi 3$ value should range 
from -87 to +97 degree. Therefore, a total of eight mutations were generated on the residue pairs, Asn469-Gly487, Gly457-Asp475, Ala426-Ala432, and Ala174-Ala186, for which the $\chi^{3}$ angle were $-77.33,80.16,-82.98$, and 94.45 degree and the energy scores were 0.52, $1.49,1.99$, and $2.04 \mathrm{kcal} / \mathrm{mol}$, respectively as described in Fig. 9.

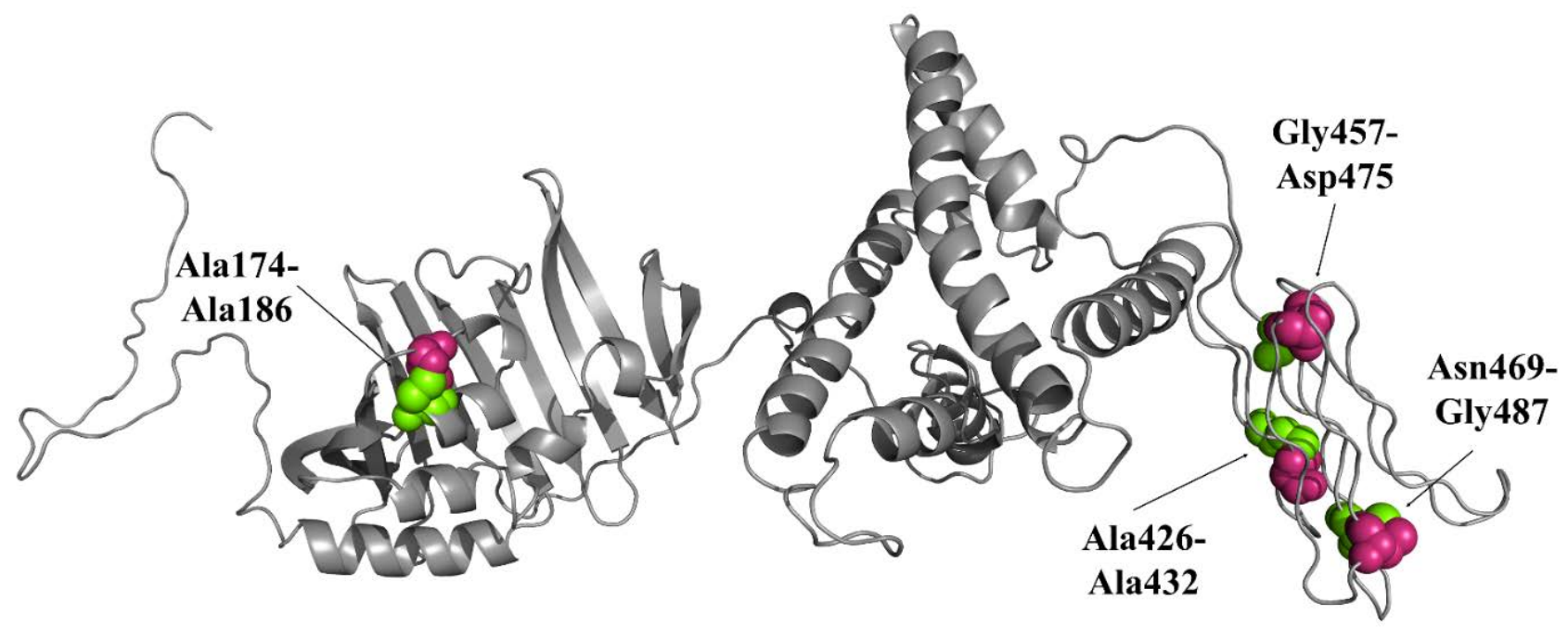

Fig. 9: Disulphide engineering of the vaccine protein. Residue pairs showed in pink (Asn569, Gly457, Ala426, and Ala 174) and light green spheres (Gly487, Asp475, Ala432, and Ala 186) were mutated to Cysteine residues to form disulphide bridge between them.

3.2.7. Interaction between vaccine construct and TLR2 receptor. A total of 30 poses of the vaccine-TLR2 complex was generated in the ClusPro docking and calculated energy score for each pose are tabulated in Table SII. The vaccine protein was found to be docked appropriately into the binding site of the TLR2 receptor in first pose (cluster_0). Moreover, the energy score for this model was found to be the lowest (-1372.6) among all predicted docked-poses, hence, considered as the best docked complex. The pose-view of the selected vaccine-TLR2 complex and their binding interactions was presented in Fig. 10. The binding interactions involved 9 hydrogen bonds, 4 electrostatic contacts, and II hydrophobic interactions. Among all hydrogen bonds, seven were classic hydrogen bonds which were provided by Gly3, Gln5, Arg7, Arg8, Arg9, MetI, Gln2, Thr6, Pro320, and Ile319 residues.

3.2.8. Binding free energy $(\Delta G)$ and dissociation constant $\left(K_{d}\right)$ : The binding interactions of the protein-protein complex depend on the binding free energy. The predicted $\Delta G$ of the vaccine-TLR2 complex was $-15.3 \mathrm{kcal} / \mathrm{mol}$ while SSL3-TLR2 complex provided $-9.0 \mathrm{kcal} / \mathrm{mol}$. Therefore, the binding affinity of the vaccine-TLR2 complex was much higher than the control and well comparable to the PRODIGY's internal dataset (https://nestor.science.uu.nl/prodigy/dataset). This prediction was parallel to the calculated dissociation constant $\left(K_{d}\right)$ 5.9e-12 M and 2.7e-07 M for vaccine-TLR2 complex and control, respectively. The $K_{d}$ is the separation rate of a protein complex into smaller parts at equilibria. The lower the $\mathrm{K}_{\mathrm{d}}$, the more tightly bound the ligand is, hence, our vaccine protein showed higher binding affinity towards the TLR2 immune receptor. 


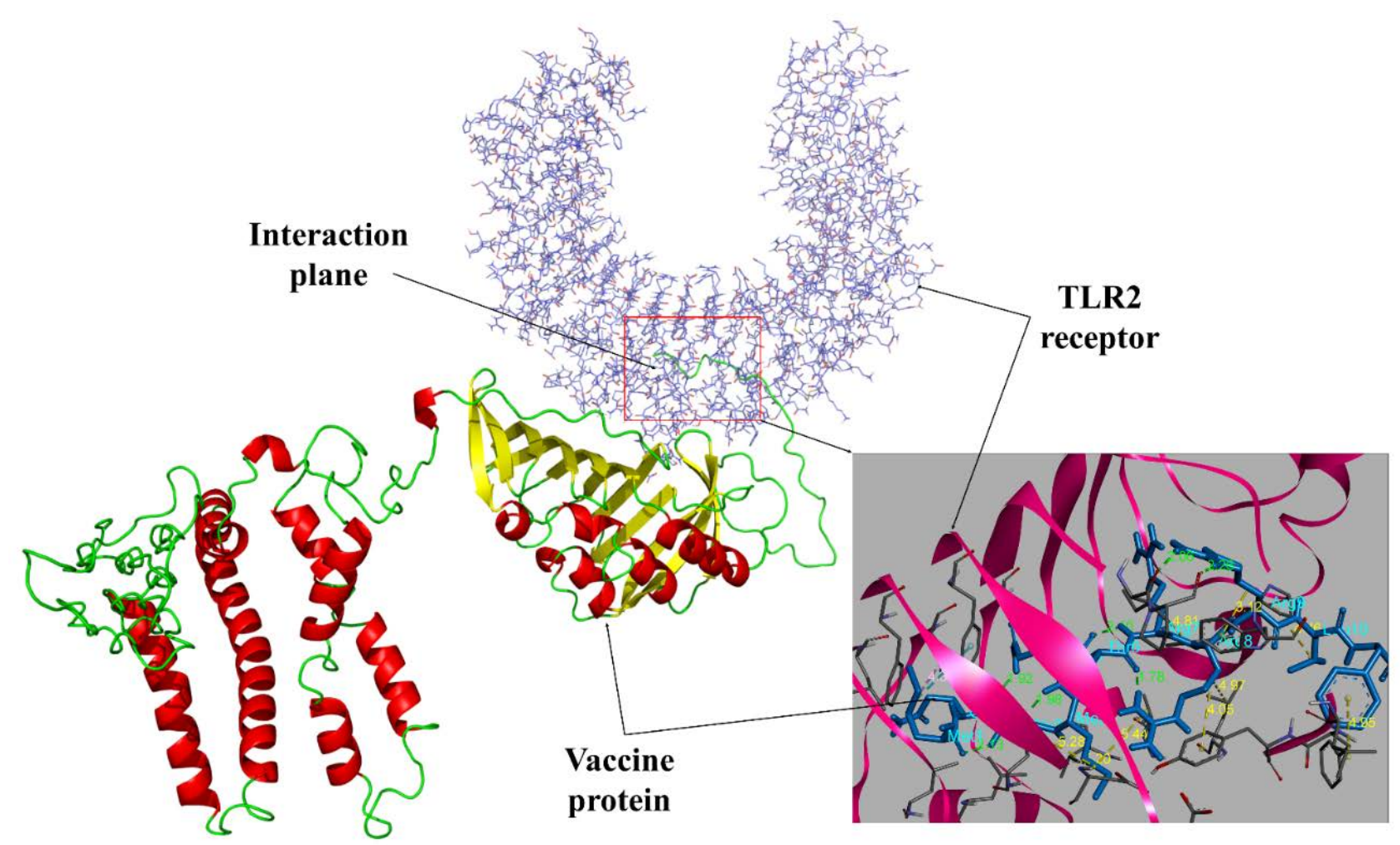

Fig. 10: Molecular docking between the vaccine protein and TLR2 immune receptor. The vaccine molecule acts as the ligand while TLR2 as the receptor. The binding interactions are represented in different colors, i.e., hydrogen bonds as green and hydrophobic bonds as yellow. The residues involved in the hydrogen bond interactions are Gly3, Gln5, Arg7, Arg8, Arg9, MetI, Gln2, Thr6, Pro320, and lle319 as shown in cyan color.

3.2.9. Structural integrity of the vaccine-TLR2 complex. The binding stability of vaccine-TLR2 complex was investigated through MD simulation and the results are shown in Fig. II and Table SI2. The simulations was carried out for 3 nanoseconds since the complex become stabilized around 2.4 nanoseconds with mild fluctuation afterwards (Fig. 9a). The average simulation energy was $-15269666.89 \mathrm{~kJ} / \mathrm{mol}$, while the Coulombic charge and van der Waals interactions were -20235278.67 and $2861791.649 \mathrm{~kJ} / \mathrm{mol}$, respectively (Table SI2). The average RMSD of the complex backbone was $7.673 \AA$ (Fig. 9a) while the RMSD of side-chain residues ranged in between $0.522 \AA$ to $10.962 \AA$ (Fig. I lb). We also calculated the RMSF to evaluate the flexibility of side-chains. The RMSF and RMSD values ranged from I.657 $\AA$ to $9.472 \AA$ and $1.997 \AA$ to $16.974 \AA$, respectively. The higher peaks at $A A_{550-600}, A_{800-850}$ and $A A_{930-950}$ in the plot indicate highly flexible regions in the complex (Fig. 9b). 
(a)

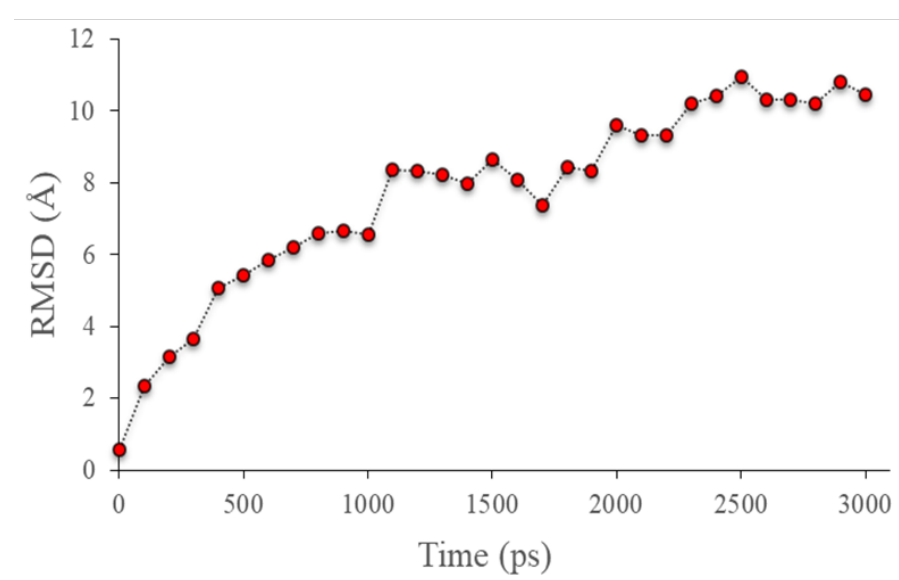

(b)

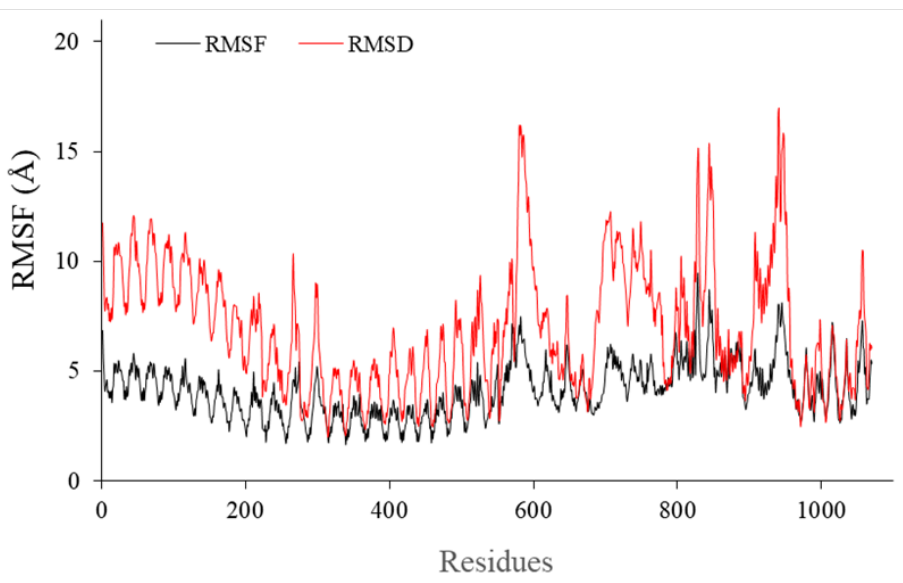

Fig. I I: Molecular dynamic simulation of the vaccine-TLR2 complex (a) RMSD value of the vaccine-TLR2 complex backbone; and (b) RMSF (black) and RMSD (red) values of side-chain residues.

3.2. I0. Immune simulation for vaccine efficacy. The computer-generated immune responses were consistent with real-life immune reactions in C-ImmSim server, where secondary and tertiary responses were higher than the primary response (Fig. 12). Both secondary and tertiary responses were characterized by the increased immunoglobulin activity (i.e., $\lg G I+\lg G 2$, IgM, and $\lg G+\lg M$ antibodies) with rapid antigen clearance (Fig. I2a). In addition, higher levels of Bcell activities, especially $B$ isotype IgM and IgGI, was observed with prominent memory cell formation (Fig. I2b,c, Fig. S2). Similarly, the number of active T-cells (both CTL and HTL) was dramatically increased during the secondary and tertiary responses and slowly decreased afterwards (Fig. 12d,e). The development of helper T-cell memory (I800 cells $/ \mathrm{mm}^{3}$ ) was the higher than that of the B-cells (500 cells $/ \mathrm{mm}^{3}$, Fig. S2). In addition, macrophage activity was rapidly increased after each exposure and reduced with antigen clearance (Fig. I2f). Furthermore, high levels of IFN- $\gamma$, IL-I0, and IL-2 were also evident (Fig. 12g). The amount and percentage of ThI type immune response was higher than Th0 type response (Fig. $12 \mathrm{~h}$ ). Moreover, repeated exposure to 12 vaccine antigens elicited increasing $\lg \mathrm{GI}$ and consistent lower activity of $\operatorname{lgM}$ and $\operatorname{lgG} 2$ immunoglobulins. Also, the amount of IFN- $\gamma$ and helper T-cell populations was higher throughout exposure (Fig. S2). All of these are relevant for immunity against M. ulcerans as we stated earlier. Therefore, the vaccine could be competent enough to control the Buruli ulcer pathogen. 
(a)

Immune response by antigen exposure

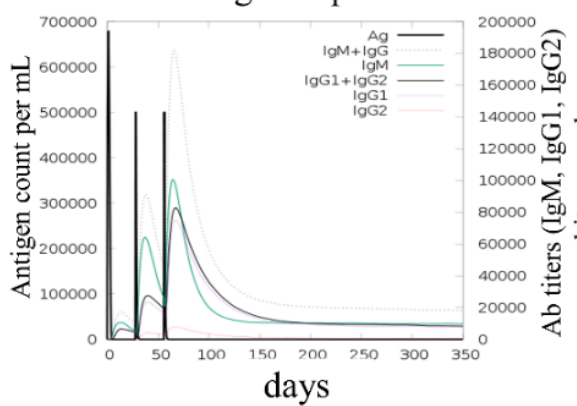

(d)

TH cell population per state $\left(\right.$ cells $\left./ \mathrm{mm}^{3}\right)$

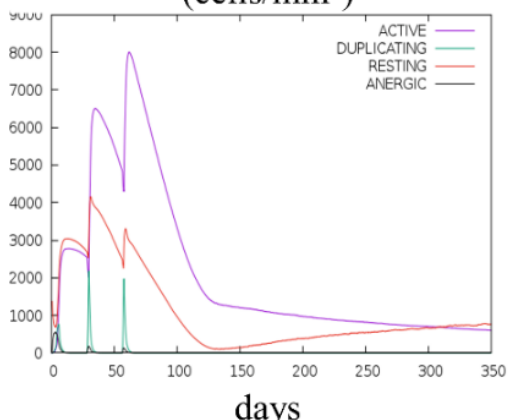

(g)

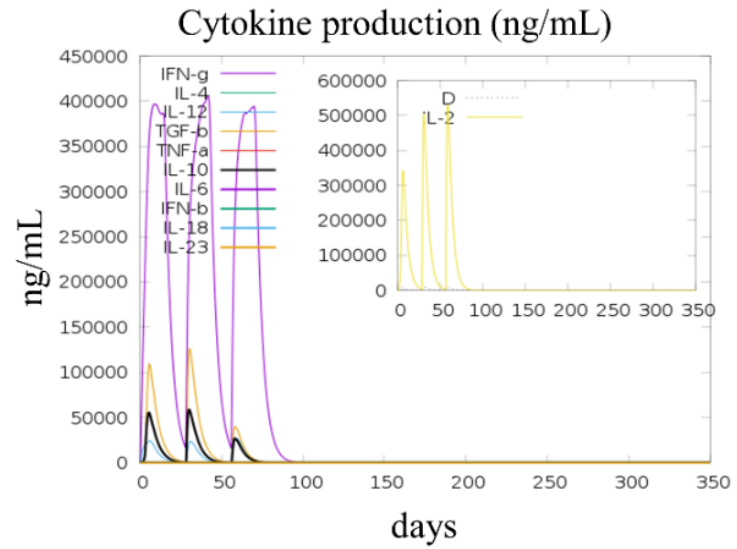

(b)

B-cell population per state (cells $/ \mathrm{mm}^{3}$ )

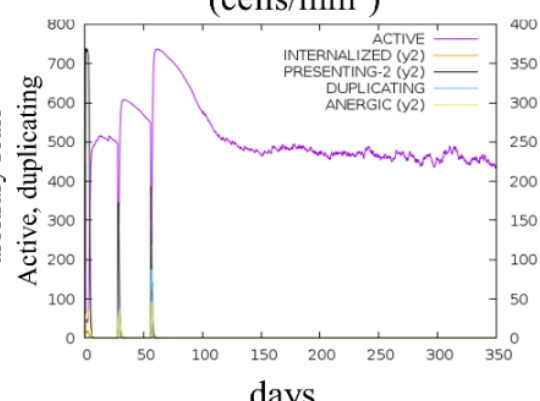

(e)

TC cell population per state (cells $/ \mathrm{mm}^{3}$ )

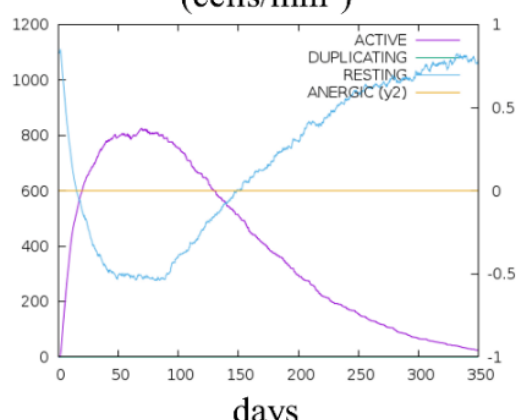

days (c)

PLB cell population (cells $/ \mathrm{mm}^{3}$ )

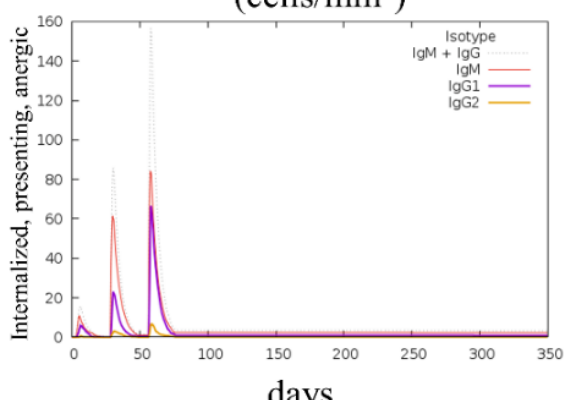

(f)

Macrophage population per state (cells $/ \mathrm{mm}^{3}$ )

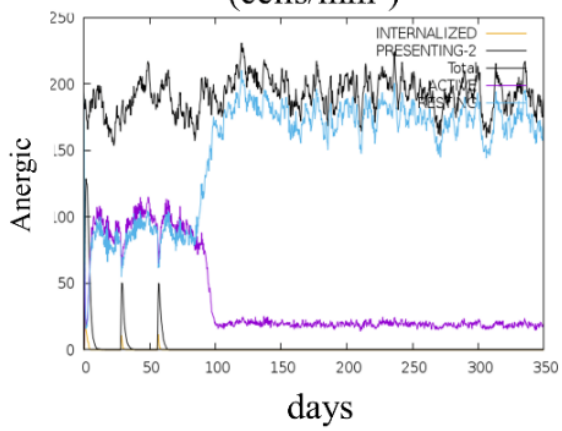

(h)
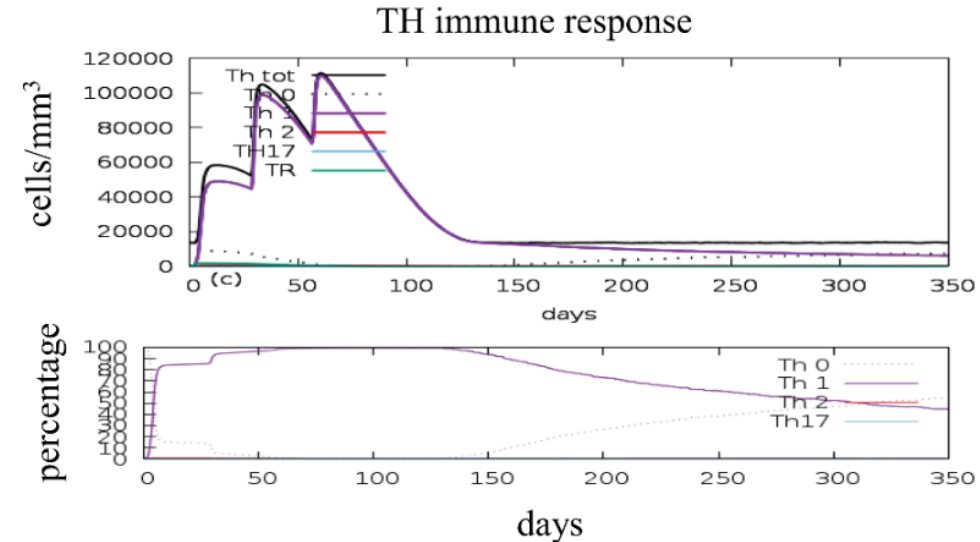

Fig. I2: In silico generation of immune response using vaccine as antigen (a) generation of immunoglobulins and B-cell isotypes upon exposure to antigen; (b) amount of active B-cell populations per state; (c) amount of plasma B-lymphocytes and their isotypes per state; (d) state of helper T-cell population during subsequent immune responses; (e) cytotoxic T-cell population per state of antigen exposure; $(f)$ activity of macrophage population in three subsequent immune responses; (g) production of cytokine and interleukins in different states with Simpson index (D); and (h) amount (cells $/ \mathrm{mm}^{3}$ ) and percentage (\%) of ThI mediated immune responses.

3.2. I I. In silico cloning within E. coli system. The main purpose of codon optimization and in silico cloning was to express the vaccine protein into the $E$. coli host system efficiently. Here, we adapted the $M$. ulcerans codons present in vaccine construct according to the codon usage of $E$. coli $\mathrm{KI} 2$ strain. The optimized codon sequence was 1560 nucleotides long. The GC-content of the improved DNA sequence was $56.60 \%$ and CAI score was 0.986 . The CAI score close to 1.0 suggested satisfactory adaptation. Later on, the optimized codon was inserted between the Xhol 
(I58) and Ncol ( I 724) restriction sites at MCS of the E. coli vector PET30a (+) as shown in Fig. I3. The target sequence is also included S-tag and His-tag residues which may help in the affinity-dependent detection and purification process. Thus, the total length of the clone was $6.93 \mathrm{kbp}$.

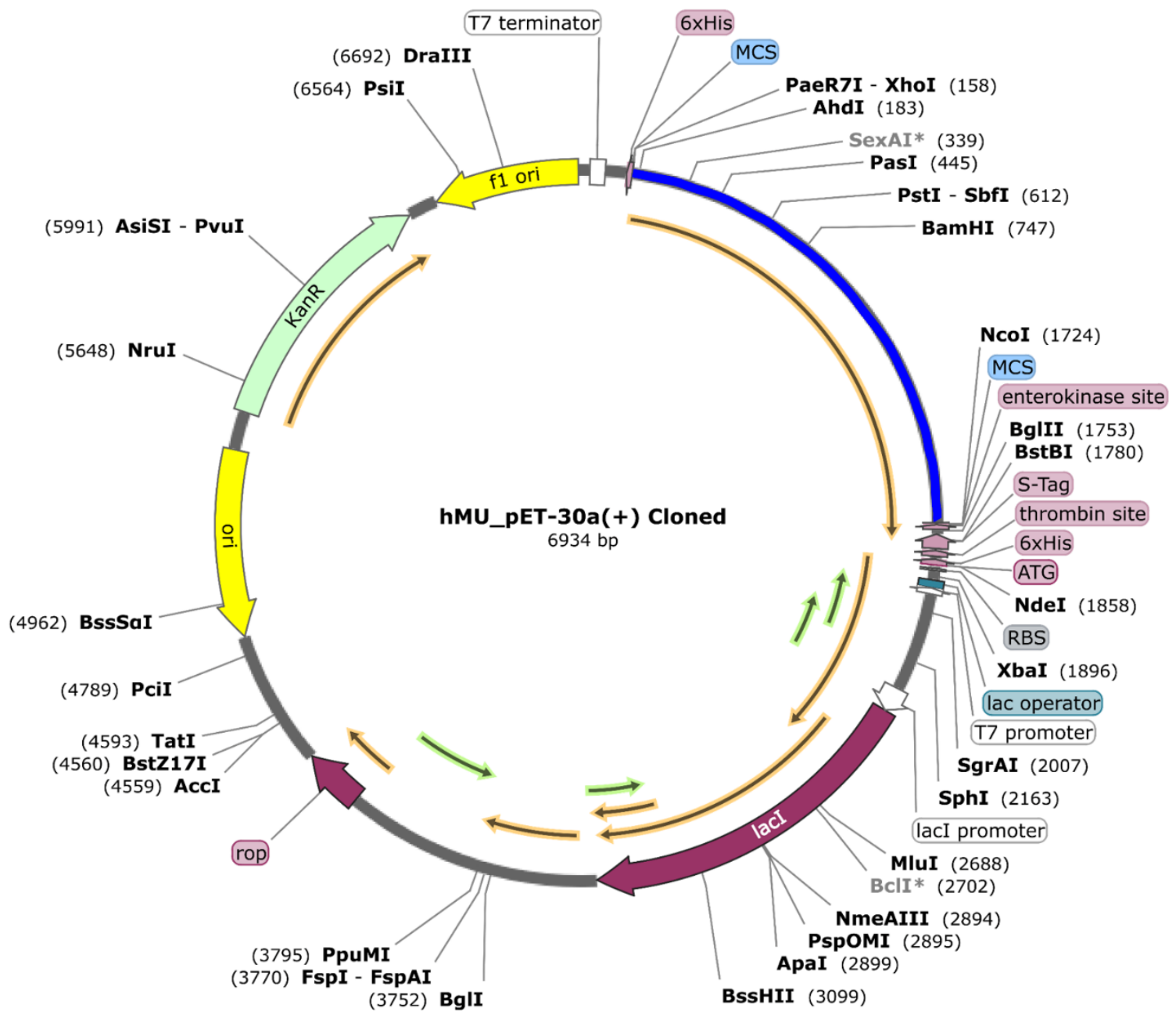

Fig. 13: In silico cloning of optimized vaccine codon into E. coli KI 2 expression system. Vaccine protein sequence was optimized and inserted into E. coli vector pET30a (+) at the position between Xhol (I58) and Ncol (1724). The inserted DNA sequence is shown in blue colour while keeping the plasmid grey colour.

\section{Discussion}

Despite being the strongest immune modalities (Nezafat et al. 2016), the development of a vaccine based on immunological experiments is relatively expensive, labor-intensive and time-consuming (Kazi et al. 2018; Plotkin et al. 2017). However, recent advances in immunological bioinformatics have resulted in viable tools and servers that can reduce the time and cost of conventional vaccine development (Kazi et al. 2018). However, the development of effective multi-epitope vaccines remains challenging due to the difficulties in the selection of appropriate antigen candidates, immunodominant epitopes and an efficient delivery system (L. Zhang 2018). Therefore, the prediction of suitable antigenic epitopes of a target protein by immunoinformatic methods is extremely important for designing a multi-epitope vaccine (Yin et al. 2016; Cherryholmes, Stanton, and Disis 2015).

In the current study, we designed a multi-epitope vaccine using the potent $\mathrm{T}$ and $\mathrm{B}$-cell epitopes derived from the highest antigenic PE-PGRS family protein of M. ulcerans. The PE-PGRS proteins belong to the PE family of conserved 
bioRxiv preprint doi: https://doi.org/10.1101/795146; this version posted October 7, 2019. The copyright holder for this preprint (which was not certified by peer review) is the author/funder, who has granted bioRxiv a license to display the preprint in perpetuity. It is made available under aCC-BY-NC-ND 4.0 International license.

mycobacterial protein featured by the presence of a polymorphic GC-rich repeating units (Sampson 20II; Brennan 2017). Although the function(s) of PE-PGRS protein is still remain elusive, emerging evidences support the association of PE/PPE proteins with several steps of mycobacterial pathogenesis (Sampson 201I; Bottai and Brosch 2009). In addition, PE-PGRSs interact with TLR2 receptor to activate the dendritic cells (DCs), macrophages and production of inflammatory cytokines like tumor necrosis factor-alpha (TNF- $\alpha$ ) that promote apoptosis and necrosis of host cells (Brennan 2017; Dheenadhayalan, Delogu, and Brennan 2006). Further, they elicit both T-cells and cross-reactive antibodies; and may involve in antigenic variation (Brennan 2017). Moreover, surface or secreted proteins like PEPGRS protein (Banu et al. 2002) are good targets of immune effector molecules due to their higher exposure to the immune system (Monterrubio-López, González-Y-Merchand, and Ribas-Aparicio 20I5). Therefore, proteins belong to PE-PGRS family may be good candidates for vaccine development (Brennan 2017). Furthermore, the number of transmembrane (TM) helix should be considered in vaccine design (He 2014; Dalsass et al. 2019). Proteins with multiple TM helices are usually discouraged because of their inefficiency in cloning, expression, and purification (MonterrubioLópez, González-Y-Merchand, and Ribas-Aparicio 2015). The selected PE-PGRS family protein had the highest antigenic score (2.394I) with no transmembrane helix, hence, considered as an appropriate candidate for vaccine design against M. ulcerans. Monterrubio-López et al. also found PE-PGRS protein to be highly antigenic and suggested as a potential vaccine candidate against Mycobacterium tuberculosis (Monterrubio-López, González-Y-Merchand, and Ribas-Aparicio 2015) However, we didn't consider mycolactone, disease causing exotoxin, for vaccine design since polyketides are not immunogenic due to their chemical structure. In addition, antibodies against mycolactone were not found either in healthy contacts or in Buruli ulcer sufferers (Huygen et al. 2009).

An ideal multi-epitope vaccine should contain both T- and B-cell epitopes for stimulating a complete network of immune responses (L. Zhang 2018). Keeping it in mind, both types of epitopes were predicted from PE-PGRS protein and evaluated with rigorous analysis. The most potent epitopes were selected based on their immunogenic properties (i.e., antigenicity, allergenicity, toxicity, and cytokine production). The number of HLA binding alleles ( 5 threshold) was also considered for the broad-spectrum functionality. However, overlapping epitopes were discarded from the final selection for allowing epitopic variability in vaccine protein. Conversely, an exception has been made in case of HTL epitopes since ThI cells are important for immunity against M. ulcerans (Fraga et al. 20I I; Nausch et al. 2017; Huygen et al. 2009). Besides, there are considerable differences in their docking affinity, binding residues, and antigenicity. For instance, overlapping HTL epitope (LSVAPDELAAAATEL) provided II hydrogen bonds and $-6.6 \mathrm{kcal} / \mathrm{mol}$ of binding affinity while epitope (SVAPDELAAAATELR) showed 13 hydrogen bonds and $-7.4 \mathrm{kcal} / \mathrm{mol}$ of binding energy. Moreover, epitope LSVAPDELAAAATEL and SVAPDELAAAATELR were involved with 15 and 18 active site residues where only 6 residues (i.e., Asp55, Asn62 Arg70, Arg77, Asn82, and Ala 10) were in common. The selected epitopes were then used for vaccine construction. On the other hand, a M. ulcerans derived lipoprotein LprG was added to the vaccine construct as an adjuvant to make vaccine more immunogenic. Therefore, it will mimic the presence of natural pathogen and improve the vaccine's immunogenicity at the same time. The effectiveness of a vaccine (e.g., BCG) is dependent on the population in which the vaccination is used (Phillips et al. 20I5). The rate of Buruli ulcer incidence is the highest in many West African countries such as Benin, Côte d'Ivoire and Ghana (Huygen et al. 2009). Moreover, it has also been reported in tropical countries of Africa, America, Asia and Australia; and non-tropical areas such as Japan and China (Huygen et al. 2009). Importantly, T-cell epitopes included in vaccine construct showed $99.8 \%$ of 
bioRxiv preprint doi: https://doi.org/10.1101/795146; this version posted October 7, 2019. The copyright holder for this preprint (which was not certified by peer review) is the author/funder, who has granted bioRxiv a license to display the preprint in perpetuity. It is made available under aCC-BY-NC-ND 4.0 International license.

world population coverage and more than $95 \%$ coverage in pathogen invaded areas including Buruli ulcer endemic regions, suggesting that the designed vaccine would be effective on majority of the world population.

The vaccine construct was found to be highly antigenic, immunogenic and non-allergenic indicating the potency of epitope vaccine in provoking robust immune responses without producing allergenic reactions. The vaccine construct has 520 amino acid residues including an adjuvant LprG which alone constitutes $24 \mathrm{I}$ residues. Chatterjee and coworkers have designed a multi-epitope vaccine which was 568 amino acid long (Chatterjee et al. 20I8). On the other hand, Kalita et al. design a multi-epitope vaccine against Fasciola gigantica which even had 765 amino acid residues (Kalita et al. 2019). Further, the multi-epitope vaccine against Schistosoma mansoni, Onchocerca volvulus, Anopheles stephensi, Leishmania parasites have been designed where the length was 617, 599, 54I, 528 amino acid long, respectively (Shey et al. 2019; Rahmani et al. 2019; Khatoon, Pandey, and Prajapati 2017). Moreover, the linkers were added to facilitate the functional preservation of each epitope ( $~ 9-15$ residues) so that they can function separately after being imported into the human body (Pandey, Bhatt, and Prajapati 2018). Therefore, our results suggest that the size of our vaccine would not be a problem in term of efficacy, stability and expression. The molecular weight of the vaccine protein was $50.78 \mathrm{kDa}$. According to theoretical PI value, the vaccine is slightly basic which may provide stable interaction in physiological $\mathrm{pH}$ range. Furthermore, estimated aliphatic index and instability index scores revealed that the vaccine protein might be stable and thermostable, while the negative grand average hydropathicity score suggested its hydrophilicity; hence, has strong interactions with water molecules. However, peptides with short half-life are the biggest problem in the development of therapeutic proteins (Mathur et al. 2016). In this study, the vaccine protein has 30 hours of half-life in mammalian reticulocytes (in vitro) while more than 20 hours in yeast (in vivo) and more than 10 hours in E. coli cells (in vivo), which is satisfactory as stated previously (Khatoon, Pandey, and Prajapati 2017; Pandey, Bhatt, and Prajapati 2018). Moreover, the recombinant proteins should be soluble on overexpression for postproduction studies (Magnan, Randall, and Baldi 2009). Importantly, both SolPro and Protein-Sol servers predicted our vaccine protein as highly soluble that ensured easy purification.

For effective transportation of vaccine into the body, strong binding affinity towards the immune receptor (i.e., TLR2) is necessary (Black et al. 2010). In this study, minimal energy $(-1372.6)$ was required by refined vaccine model for locating the binding site of TLR2 receptor appropriately. Moreover, binding free energy $(-15.3 \mathrm{kcal} / \mathrm{mol})$ and dissociation rate constant (5.9e-12 M) scores were lower than that of the control that further confirmed the higher binding affinity between the vaccine and TLR2 receptor. Furthermore, the vaccine-TLR2 complex was found to be stable during MD simulation where protein backbone undergone some microscale-changes $(\sim 7.67 \AA)$ and mild fluctuations in their side-chain residues that can occur due to the flexible regions (Khatoon, Pandey, and Prajapati 2017; Pandey, Bhatt, and Prajapati 2018). These results are in line with the previous study where stabilization of vaccinereceptor complex was achieved within similar time-scale (M. Ali et al. 20I7; Mirza et al. 2016). The hydrogen bond helps in molecular recognition by providing specificity and directionality to the interaction (Hubbard and Kamran Haider 2010). Thus, the presence of multiple hydrogen bonds on the vaccine and TLR2 interaction plane suggested their precise binding. The stability of the vaccine protein was also improved by creating 4 disulfide bridges. Therefore, our data suggest that the vaccine protein will be able to provide stable binding interactions. 
bioRxiv preprint doi: https://doi.org/10.1101/795146; this version posted October 7, 2019. The copyright holder for this preprint (which was not certified by peer review) is the author/funder, who has granted bioRxiv a license to display the preprint in perpetuity. It is made available under aCC-BY-NC-ND 4.0 International license.

A multi-epitope vaccine should be able to elicit both T-cells (i.e., CTL and HTL) and B-cells for effective immune responses (L. Zhang 2018). The control of Buruli ulcer is largely depends on the cellular immunity involving activated macrophages and ThI type immune response through cytokine production (Gooding et al. 200I; Huygen et al. 2009; Prévot et al. 2004; Yeboah-Manu et al. 2006). Computer simulation of immune response triggered by our vaccine protein showed increased macrophage activity and longer-lasting ThI-mediated immune reactions that are essential for M. ulcerans clearance (Hirayama, lida, and Nakase 2018). The active helper T-cell population was increasingly higher in secondary and tertiary responses compared to the primary response. In addition to T-cells, antibodies also provide protection against extracellular M. ulcerans (Huygen et al. 2009). Interestingly, the multi-epitope vaccine has 12 conformational B-cell epitopes throughout its three protein domains. Furthermore, we observed a plethora of active immunoglobulins i.e., IgM and IgG and their isotypes which could contribute to isotype switching. Therefore, the simulated immune response was characterized by higher levels of helper T-cells and B-cells activities. These results coincide with the previous findings where PE-PGRS proteins from $M$. tuberculosis were used to trigger immune response in silico (Monterrubio-López, González-Y-Merchand, and Ribas-Aparicio 2015). As in tuberculosis and leprosy, the macrophage activating cytokine IFN- $\gamma$ seems to play a pivotal role in the control of $M$. ulcerans infection. However, whole M. ulcerans had shown reduced amount of IFN- $\gamma$ production upon in vitro stimulation (Gooding et al. 200I; Huygen et al. 2009; Prévot et al. 2004). In a study on mouse model, mycolactone has been observed to attack mononuclear cells (i.e., lymphocytes, monocytes, DCs and macrophages) and thus interfere with cellular immunity in the immunosuppressed host (Hong et al. 2008). Thus, mycolactone affects human lymphocytes and macrophages to inhibit the production of IL-2 and TNF- $\alpha$, respectively (Coutanceau et al. 2005; Torrado et al. 2007). Besides, it also interrupts DCs to prime cell-mediated immunity and produces chemotactic inflammatory signals (Coutanceau et al. 2007). Importantly, IFN- $p$ production by newly designed vaccine was the highest among other cytokines. Furthermore, prominent activity of IL-2 and IL-10 was also observed. However, the peptide vaccine was not able to induce TNF- $\alpha$ production through macrophage activation. In endemic or pathogen invaded regions, the simulated immune response showed rapid antigen clearance and strong protection against M. ulcerans (Fig. S2). Moreover, the negligible Simpson index (D) suggests a diverse immune response (Rapin et al. 2010) which is plausible since the vaccine chimera contained multiple B and T-cell epitopes.

The translational efficiency of foreign genes may differ within the host system due to the incompatibility of mRNA codons which necessitates the optimization of codon for higher expression (Pandey, Bhatt, and Prajapati 2018). Satisfactorily, the obtained CAI value (0.986) was very close to 1.0 and GC contents $(56.60 \%)$ was also within the optimal limit (30-70\%) indicating possible higher expression within E. coli KI2 system (Shey et al. 2019; Morla, Makhija, and Kumar 2016). As a suggestion for prospective vaccine synthesis, in silico cloning was also performed using PET30a $(+)$ vector. This plasmid has both His-tag and S-tag as fusion partners that facilitate the ease of purification (Hengen 1995; Raines et al. 2000). Besides, S-tag sequence increases protein stability by providing its abundance of charged and polar residues (Raines et al. 2000). Moreover, in silico cloning with pET30a $(+)$ vector was described earlier (Shey et al. 2019). 


\section{Conclusions}

This study was performed to design an effective vaccine against $M$. ulcerans as a Buruli ulcer prophylaxis using integrated vaccinomics approach. The designed vaccine has antigenic, immunogenic, non-allergenic and non-toxic properties with higher binding affinity towards TLR2 immune receptor. Moreover, the vaccine was found stable at physiological $\mathrm{pH}$ range. In addition, disulfide bridges were created for structural improvement and in silico cloning was performed to ensure good expression in widely used $E$. coli $\mathrm{K} 12$ system. Furthermore, the simulated immune response was diverse and characterized by cellular and humoral immune responses with efficient memory cell formation. However, the current study is the sole outcome of an integrated vaccinomics approach; therefore, it needs experimental validation to prove the efficacy and safeness of the designed vaccine which may include the synthesis of vaccine protein followed by the rigorous assessment in vitro and in vivo.

\section{Conflicts of interest}

There are no conflicts to declare.

\section{Funding}

This research did not receive any specific grant from funding agencies in the public, commercial, or not-for-profit sectors.

\section{Author Contributions}

Study design: ZN and UKA; Immunoinformatic analysis and draft manuscript: ZN; Critical revision: MMK and MKS; Study supervision: UKA. All authors approved the final manuscript.

\section{References}

Adhikari, Utpal Kumar, and M. Mizanur Rahman. 2017. "Overlapping CD8 + and CD4 + T-Cell Epitopes Identification for the Progression of Epitope-Based Peptide Vaccine from Nucleocapsid and Glycoprotein of Emerging Rift Valley Fever Virus Using Immunoinformatics Approach." Infection, Genetics and Evolution 56 (December): 75-9l. https://doi.org/I0.1016/j.meegid.2017.10.022.

Adhikari, Utpal Kumar, Mourad Tayebi, and M. Mizanur Rahman. 2018. "Immunoinformatics Approach for EpitopeBased Peptide Vaccine Design and Active Site Prediction against Polyprotein of Emerging Oropouche Virus." Journal of Immunology Research 2018 (October): I-22. https://doi.org/ I 0.I I55/2018/67I8083.

Adusumilli, Sarojini, Armand Mve-Obiang, Tim Sparer, Wayne Meyers, John Hayman, and Pamela Long Claus Small. 2005. "Mycobacterium Ulcerans Toxic Macrolide, Mycolactone Modulates the Host Immune Response and Cellular Location of M. Ulcerans in Vitro and in Vivo." Cellular Microbiology 7 (9): 1295-1304. https://doi.org/I0.1 I I I/j. I 462-5822.2005.00557.x.

Ali, Arif, Abbas Khan, Aman Chandra Kaushik, Yanjie Wang, Syed Shujait Ali, Muhammad Junaid, Shoaib Saleem, William C. S. Cho, Xueying Mao, and Dong-Qing Wei. 2019. "Immunoinformatic and Systems Biology Approaches to Predict and Validate Peptide Vaccines against Epstein-Barr Virus (EBV)." Scientific Reports 9 (I): 720. https://doi.org/I0.1038/s4I598-0I8-37070-z.

Ali, Mudassar, Rajan Kumar Pandey, Nazia Khatoon, Aruna Narula, Amit Mishra, and Vijay Kumar Prajapati. 2017. "Exploring Dengue Genome to Construct a Multi-Epitope Based Subunit Vaccine by Utilizing Immunoinformatics Approach to Battle against Dengue Infection." Scientific Reports 7 (I): 9232. https://doi.org/10.1038/s41598-01709199-w.

Arai, R, H Ueda, A Kitayama, N Kamiya, and T Nagamune. 200I. "Design of the Linkers Which Effectively Separate Domains of a Bifunctional Fusion Protein." Protein Engineering 14 (8): 529-32. http://www.ncbi.nlm.nih.gov/pubmed/II 579220. 
bioRxiv preprint doi: https://doi.org/10.1101/795146; this version posted October 7, 2019. The copyright holder for this preprint (which was not certified by peer review) is the author/funder, who has granted bioRxiv a license to display the preprint in perpetuity. It is made available under aCC-BY-NC-ND 4.0 International license.

Banu, Sayera, Nadine Honoré, Brigitte Saint-Joanis, Dana Philpott, Marie-Christine Prévost, and Stewart T Cole. 2002. "Are the PE-PGRS Proteins of Mycobacterium Tuberculosis Variable Surface Antigens?" Molecular Microbiology 44 (I): 9-19. https://doi.org//0.1046/j.I365-2958.2002.028I3.x.

Barksby, Rebecca. 2019. "WHO Takes a New Approach to Buruli Ulcer." The Lancet. Infectious Diseases 19 (5): $473-$ 74. https://doi.org/I0.1016/SI473-3099(19)30180-X.

Berman, H. M., John Westbrook, Zukang Feng, Gary Gilliland, T. N. Bhat, Helge Weissig, llya N. Shindyalov, and Philip E. Bourne. 2000. "The Protein Data Bank." Nucleic Acids Research 28 (I): 235-42. https://doi.org// 0.1093/nar/28.1.235.

Black, Matthew, Amanda Trent, Matthew Tirrell, and Colleen Olive. 2010. "Advances in the Design and Delivery of Peptide Subunit Vaccines with a Focus on Toll-like Receptor Agonists." Expert Review of Vaccines. https://doi.org/I0.1586/erv.09.160.

Bottai, Daria, and Roland Brosch. 2009. "Mycobacterial PE, PPE and ESX Clusters: Novel Insights into the Secretion of These Most Unusual Protein Families." Molecular Microbiology 73 (3): 325-28. https://doi.org/I0.1III/j.I3652958.2009.06784.x.

Brennan, Michael J. 2017. "The Enigmatic PE/PPE Multigene Family of Mycobacteria and Tuberculosis Vaccination." Infection and Immunity. American Society for Microbiology. https://doi.org/I 0. I I 28/IAI.00969-16.

Buchan, Daniel W. A., Federico Minneci, Tim C. O. Nugent, Kevin Bryson, and David T. Jones. 2013. "Scalable Web Services for the PSIPRED Protein Analysis Workbench." Nucleic Acids Research 4I (WI): W349-57. https://doi.org//0.1093/nar/gkt38I.

Bui, Huynh-Hoa, John Sidney, Kenny Dinh, Scott Southwood, Mark J Newman, and Alessandro Sette. 2006. "Predicting Population Coverage of T-Cell Epitope-Based Diagnostics and Vaccines." BMC Bioinformatics 7 (I): I53. https://doi.org/I0.1 I86/I47I-2I05-7-I53.

Calis, Jorg J. A., Matt Maybeno, Jason A. Greenbaum, Daniela Weiskopf, Aruna D. De Silva, Alessandro Sette, Can Keșmir, and Bjoern Peters. 2013. "Properties of MHC Class I Presented Peptides That Enhance Immunogenicity." Edited by Becca Asquith. PLoS Computational Biology 9 (10): el003266. https://doi.org//0.I37I/journal.pcbi. I003266.

Castiglione, F., F. Mantile, P. De Berardinis, and A. Prisco. 2012. "How the Interval between Prime and Boost Injection Affects the Immune Response in a Computational Model of the Immune System." Computational and Mathematical Methods in Medicine 2012 (September): I-9. https://doi.org/I0.II55/20I2/842329.

Chatterjee, Nina, Rupal Ojha, Nazia Khatoon, and Vijay Kumar Prajapati. 2018. "Scrutinizing Mycobacterium Tuberculosis Membrane and Secretory Proteins to Formulate Multiepitope Subunit Vaccine against Pulmonary Tuberculosis by Utilizing Immunoinformatic Approaches." International Journal of Biological Macromolecules II 8 (October): 180-88. https://doi.org/10.1016/j.ijbiomac.2018.06.080.

Chaudhri, Geeta, Ben J. Quah, Yang Wang, Abel H. Y. Tan, Jie Zhou, Gunasegaran Karupiah, and Christopher R. Parish. 2009. "T Cell Receptor Sharing by Cytotoxic T Lymphocytes Facilitates Efficient Virus Control." Proceedings of the National Academy of Sciences of the United States of America 106 (35): 14984. https://doi.org/I0.1073/PNAS.0906554I06.

Chen, I-Min A, Ken Chu, Krishna Palaniappan, Manoj Pillay, Anna Ratner, Jinghua Huang, Marcel Huntemann, et al. 2019. "IMG/M v.5.0: An Integrated Data Management and Comparative Analysis System for Microbial Genomes and Microbiomes." Nucleic Acids Research 47 (DI): D666-77. https://doi.org/ I0.1093/nar/gky90I.

Cherryholmes, Gregory A., Sasha E. Stanton, and Mary L. Disis. 2015. "Current Methods of Epitope Identification for Cancer Vaccine Design.” Vaccine 33 (5I): 7408-I4. https://doi.org/I 0.1016/j.vaccine.20I5.06.II6.

Chuang, Gwo Yu, Dima Kozakov, Ryan Brenke, Stephen R. Comeau, and Sandor Vajda. 2008. "DARS (Decoys As the Reference State) Potentials for Protein-Protein Docking." Biophysical Journal 95 (9): 42/7-27. https://doi.org/I0.1529/biophysj. I08.1358/4.

Coffman, Robert L., Alan Sher, and Robert A. Seder. 2010. "Vaccine Adjuvants: Putting Innate Immunity to Work." Immunity 33 (4): 492-503. https://doi.org/I0.1016/j.immuni.2010.10.002.

Colovos, Chris, and Todd O. Yeates. 1993. "Verification of Protein Structures: Patterns of Nonbonded Atomic Interactions." Protein Science 2 (9): I5I I-19. https://doi.org/I0.1002/pro.5560020916.

Cooper, Max D. 2015. "The Early History of B Cells." Nature Reviews Immunology I5 (3): 19I-97. https://doi.org//0.1038/nri380I.

Coutanceau, Emmanuelle, Jeremie Decalf, Angelo Martino, Aurélie Babon, Nathalie Winter, Stewart T. Cole, Matthew L. Albert, and Caroline Demangel. 2007. "Selective Suppression of Dendritic Cell Functions by Mycobacterium Ulcerans Toxin Mycolactone." Journal of Experimental Medicine 204 (6): 1395-1403. https://doi.org// 0.1084/jem.20070234.

Coutanceau, Emmanuelle, Pierre Legras, Laurent Marsollier, Gilles Reysset, Stewart T Cole, and Caroline Demangel. 2006. "Immunogenicity of Mycobacterium Ulcerans Hsp65 and Protective Efficacy of a Mycobacterium Leprae Hsp65-Based DNA Vaccine against Buruli Ulcer." Microbes and Infection 8 (8): 2075-8I. https://doi.org/I0.1016/j.micinf.2006.03.009.

Coutanceau, Emmanuelle, Laurent Marsollier, Roland Brosch, Emmanuelle Perret, Pierre Goossens, Myriam Tanguy, 
bioRxiv preprint doi: https://doi.org/10.1101/795146; this version posted October 7, 2019. The copyright holder for this preprint (which was not certified by peer review) is the author/funder, who has granted bioRxiv a license to display the preprint in perpetuity. It is made available under aCC-BY-NC-ND 4.0 International license.

Stewart T Cole, Pamela L C Small, and Caroline Demangel. 2005. "Modulation of the Host Immune Response by a Transient Intracellular Stage of Mycobacterium Ulcerans: The Contribution of Endogenous Mycolactone Toxin." Cellular Microbiology 7 (8): I I87-96. https://doi.org/ I 0.I I I I/j.I 462-5822.2005.00546.x.

Craig, Douglas B, and Alan A Dombkowski. 2013. "Disulfide by Design 2.0: A Web-Based Tool for Disulfide Engineering in Proteins." BMC Bioinformatics I4 (I): 346. https://doi.org/I0.I I86/I47/-2I05-I4-346.

Dalsass, Mattia, Alessandro Brozzi, Duccio Medini, and Rino Rappuoli. 2019. "Comparison of Open-Source Reverse Vaccinology Programs for Bacterial Vaccine Antigen Discovery." Frontiers in Immunology 10 (FEB). https://doi.org/l0.3389/fimmu.2019.00II3.

Dhanda, Sandeep Kumar, Sudheer Gupta, Pooja Vir, and G. P. S. Raghava. 20I3. "Prediction of IL4 Inducing Peptides." Clinical and Developmental Immunology 2013: I-9. https://doi.org/ I0.I I55/2013/263952.

Dhanda, Sandeep Kumar, Pooja Vir, and Gajendra PS Raghava. 2013. "Designing of Interferon-Gamma Inducing MHC Class-II Binders.” Biology Direct 8 (I): 30. https://doi.org/I0.1 I86/I745-6I50-8-30.

Dheenadhayalan, Veerabadran, Giovanni Delogu, and Michael J Brennan. 2006. "Expression of the PE_PGRS 33 Protein in Mycobacterium Smegmatis Triggers Necrosis in Macrophages and Enhanced Mycobacterial Survival." Microbes and Infection 8 (I): 262-72. https://doi.org/I0.1016/j.micinf.2005.06.02I.

Dickson, Callum J., Benjamin D. Madej, Åge A. Skjevik, Robin M. Betz, Knut Teigen, lan R. Gould, and Ross C. Walker. 2014. "LipidI4: The Amber Lipid Force Field." Journal of Chemical Theory and Computation 10 (2): 865-79. https://doi.org/10.1021/ct4010307.

Dimitrov, I., L. Naneva, I. Doytchinova, and I. Bangov. 2014. "AllergenFP: Allergenicity Prediction by Descriptor Fingerprints." Bioinformatics 30 (6): 846-5I. https://doi.org//0.1093/bioinformatics/btt6/9.

Dormitzer, Philip R, Jeffrey B Ulmer, and Rino Rappuoli. 2008. "Structure-Based Antigen Design: A Strategy for next Generation Vaccines." Trends in Biotechnology 26 (I2): 659-67. https://doi.org//0.1016/j.tibtech.2008.08.002.

Doytchinova, Irini A, and Darren R Flower. 2007. "VaxiJen: A Server for Prediction of Protective Antigens, Tumour Antigens and Subunit Vaccines." BMC Bioinformatics 8 (I): 4. https://doi.org/I 0.1 I86//47/-2 I 05-8-4.

Fraga, Alexandra G., Teresa G. Martins, Egídio Torrado, Kris Huygen, Françoise Portaels, Manuel T. Silva, António G. Castro, and Jorge Pedrosa. 2012. "Cellular Immunity Confers Transient Protection in Experimental Buruli Ulcer Following BCG or Mycolactone-Negative Mycobacterium Ulcerans Vaccination." PLoS ONE 7 (3). https://doi.org//0.137I/journal.pone.0033406.

Fraga, Alexandra G, Andrea Cruz, Teresa G Martins, Egídio Torrado, Margarida Saraiva, Daniela R Pereira, Wayne M Meyers, et al. 201 I. "Mycobacterium Ulcerans Triggers T-Cell Immunity Followed by Local and Regional but Not Systemic Immunosuppression." Infection and Immunity 79 (I): 42 I-30. https://doi.org/I0.I I 28/IAI.00820-I0.

Gehring, Adam J, Karen M Dobos, John T Belisle, Clifford V Harding, and W Henry Boom. 2004. "Mycobacterium Tuberculosis LprG (RvI4IIc): A Novel TLR-2 Ligand That Inhibits Human Macrophage Class II MHC Antigen Processing." Journal of Immunology (Baltimore, Md.: 1950) 173 (4): 2660-68. https://doi.org// 0.4049/jimmunol. 173.4.2660.

George, K M, D Chatterjee, G Gunawardana, D Welty, J Hayman, R Lee, and P L Small. 1999. "Mycolactone: A Polyketide Toxin from Mycobacterium Ulcerans Required for Virulence.” Science (New York, N.Y.) 283 (5403): 854-57. https://doi.org//0.II 26/science.283.5403.854.

Gnjatic, Sacha, Nikhil B. Sawhney, and Nina Bhardwaj. 2010. "Toll-like Receptor Agonists Are They Good Adjuvants?" Cancer Journal. https://doi.org/I0.1097/PPO.0b0 I 3e3I8I eaca65.

Gooding, T. M., P. D R Johnson, D. E. Campbell, J. A. Hayman, E. L. Hartland, A. S. Kemp, and R. M. Robins-Browne. 200I. "Immune Response to Infection with Mycobacterium Ulcerans." Infection and Immunity 69 (3): I704-7. https://doi.org/I0.II 28/IAI.69.3.1704-I707.200I.

Grote, Andreas, Karsten Hiller, Maurice Scheer, Richard Münch, Bernd Nörtemann, Dietmar C Hempel, and Dieter Jahn. 2005. "JCat: A Novel Tool to Adapt Codon Usage of a Target Gene to Its Potential Expression Host." Nucleic Acids Research 33 (Web Server issue): W526-3I. https://doi.org/I0.1093/nar/gki376.

Gu, Yuan, Ximeng Sun, Bo Li, Jingjing Huang, Bin Zhan, and Xinping Zhu. 2017. "Vaccination with a Paramyosin-Based Multi-Epitope Vaccine Elicits Significant Protective Immunity against Trichinella Spiralis Infection in Mice.” Frontiers in Microbiology 8: I475. https://doi.org//0.3389/fmicb.20I7.0I475.

Gupta, Sudheer, Pallavi Kapoor, Kumardeep Chaudhary, Ankur Gautam, Rahul Kumar, Gajendra P. S. Raghava, and Gajendra P S Raghava. 2013. "In Silico Approach for Predicting Toxicity of Peptides and Proteins." Edited by Randen Lee Patterson. PLoS ONE 8 (9): e73957. https://doi.org/I0.137//journal.pone.0073957.

Hart, Bryan E., Laura P. Hale, and Sunhee Lee. 2016. "Immunogenicity and Protection Conferred by a Recombinant Mycobacterium Marinum Vaccine against Buruli Ulcer.” Trials in Vaccinology 5: 88-91. https://doi.org/I0.1016/j.trivac.2016.04.00I.

He, Yongqun. 2014. "Bacterial Whole-Genome Determination and Applications." In Molecular Medical Microbiology: Second Edition, I-3:357-68. Elsevier Ltd. https://doi.org/I0.1016/B978-0-I2-397I69-2.00020-2.

Hebditch, Max, M. Alejandro Carballo-Amador, Spyros Charonis, Robin Curtis, and Jim Warwicker. 2017. "ProteinSol: A Web Tool for Predicting Protein Solubility from Sequence." Bioinformatics 33 (19): 3098-3100. https://doi.org// 0.1093/bioinformatics/btx345. 
Hengen, P. 1995. "Purification of His-Tag Fusion Proteins from Escherichia Coli." Trends in Biochemical Sciences 20 (7): 285-86. https://doi.org/10.1016/s0968-0004(00)89045-3.

Hirayama, Daisuke, Tomoya lida, and Hiroshi Nakase. 2018. "The Phagocytic Function of Macrophage-Enforcing Innate Immunity and Tissue Homeostasis." International Journal of Molecular Sciences. MDPI AG. https://doi.org/10.3390/ijms I 9010092.

Hong, Hui, Emmanuelle Coutanceau, Marion Leclerc, Laxmee Caleechurn, Peter F. Leadlay, and Caroline Demangel. 2008. "Mycolactone Diffuses from Mycobacterium Ulcerans-Infected Tissues and Targets Mononuclear Cells in Peripheral Blood and Lymphoid Organs." PLoS Neglected Tropical Diseases 2 (10). https://doi.org//0.137I/journal.pntd.0000325.

Hubbard, Roderick E, and Muhammad Kamran Haider. 2010. "Hydrogen Bonds in Proteins: Role and Strength." In Encyclopedia of Life Sciences. Chichester, UK: John Wiley \& Sons, Ltd. https://doi.org/I0.1002/9780470015902.a00030I I.pub2.

Huygen, Kris, Ohene Adjei, Dissou Affolabi, Gisela Bretzel, Caroline Demangel, Bernhard Fleischer, Roch Christian Johnson, et al. 2009. "Buruli Ulcer Disease: Prospects for a Vaccine." Medical Microbiology and Immunology 198 (2): 69-77. https://doi.org/10.1007/s00430-009-0109-6.

Ikram, Aqsa, Tahreem Zaheer, Faryal Mehwish Awan, Ayesha Obaid, Anam Naz, Rumeza Hanif, Rehan Zafar Paracha, Amjad Ali, Abdul Khaliq Naveed, and Hussnain Ahmed Janjua. 2018. "Exploring NS3/4A, NS5A and NS5B Proteins to Design Conserved Subunit Multi-Epitope Vaccine against HCV Utilizing Immunoinformatics Approaches." Scientific Reports 2018 8:I 8 (I): 16107. https://doi.org/I0.1038/s4I598-0I8-34254-5.

Jacob, C O, M Leitner, A Zamir, D Salomon, and R Arnon. 1985. "Priming Immunization against Cholera Toxin and E. Coli Heat-Labile Toxin by a Cholera Toxin Short Peptide-Beta-Galactosidase Hybrid Synthesized in E. Coli." The EMBO Journal 4 (I2): 3339-43. http://www.ncbi.nlm.nih.gov/pubmed/3004953.

Johnson, Paul D.R. 2019. "Buruli Ulcer: Here Today but Where Tomorrow?” The Lancet Global Health. Elsevier Ltd. https://doi.org/I0.1016/S22I4-109X(19)30233-5.

Kaisho, Tsuneyasu, and Shizuo Akira. 2002. "Toll-like Receptors as Adjuvant Receptors." Biochimica et Biophysica Acta I589 (I): I-13. https://doi.org/I0.1016/s0167-4889(0I)00I82-3.

Kalita, Parismita, Denzelle Lee Lyngdoh, Aditya K. Padhi, Harish Shukla, and Timir Tripathi. 2019. "Development of Multi-Epitope Driven Subunit Vaccine against Fasciola Gigantica Using Immunoinformatics Approach." International Journal of Biological Macromolecules 138 (October): 224-33. https://doi.org//0.1016/j.ijbiomac.2019.07.024.

Källberg, Morten, Haipeng Wang, Sheng Wang, Jian Peng, Zhiyong Wang, Hui Lu, and Jinbo Xu. 20I2. "Template-Based Protein Structure Modeling Using the RaptorX Web Server." Nature Protocols 7 (8): 15II-22. https://doi.org/I0.1038/nprot.20I2.085.

Kastritis, Panagiotis L., and Alexandre M.J.J. Bonvin. 2013. "On the Binding Affinity of Macromolecular Interactions: Daring to Ask Why Proteins Interact." Journal of the Royal Society Interface. Royal Society. https://doi.org// 0.1098/rsif.2012.0835.

Kazi, Ada, Candy Chuah, Abu Bakar Abdul Majeed, Chiuan Herng Leow, Boon Huat Lim, and Chiuan Yee Leow. 2018. "Current Progress of Immunoinformatics Approach Harnessed for Cellular- and Antibody-Dependent Vaccine Design." Pathogens and Global Health. Taylor and Francis Ltd. https://doi.org/I 0.1080/20477724.20 I8.1446773.

Khatoon, Nazia, Rajan Kumar Pandey, and Vijay Kumar Prajapati. 2017. "Exploring Leishmania Secretory Proteins to Design B and T Cell Multi-Epitope Subunit Vaccine Using Immunoinformatics Approach." Scientific Reports 2017 7:I 7 (I): 8285. https://doi.org/10.1038/s41598-017-08842-w.

Ko, J., H. Park, L. Heo, and C. Seok. 2012. "GalaxyWEB Server for Protein Structure Prediction and Refinement." Nucleic Acids Research 40 (WI): W294-97. https://doi.org/ 10. 1093/nar/gks493.

Kozakov, Dima, David R Hall, Bing Xia, Kathryn A Porter, Dzmitry Padhorny, Christine Yueh, Dmitri Beglov, and Sandor Vajda. 2017. “The ClusPro Web Server for Protein-Protein Docking.” Nature Protocols 12 (2): 255-78. https://doi.org/10.1038/nprot.2016.169.

Krieger, Elmar, Tom Darden, Sander B. Nabuurs, Alexei Finkelstein, and Gert Vriend. 2004. "Making Optimal Use of Empirical Energy Functions: Force-Field Parameterization in Crystal Space.” Proteins: Structure, Function, and Bioinformatics 57 (4): 678-83. https://doi.org//0.1002/prot.2025I.

Krogh, Anders, Björn Larsson, Gunnar Von Heijne, and Erik L.L. Sonnhammer. 200I. "Predicting Transmembrane Protein Topology with a Hidden Markov Model: Application to Complete Genomes.” Journal of Molecular Biology 305 (3): 567-80. https://doi.org// 0.1006/jmbi.2000.43I5.

Kumar, Sudeep, Raju Sunagar, and Edmund Gosselin. 2019. "Bacterial Protein Toll-like-Receptor Agonists: A Novel Perspective on Vaccine Adjuvants." Frontiers in Immunology. Frontiers Media S.A. https://doi.org/I0.3389/fimmu.2019.01 I44.

Lamiable, Alexis, Pierre Thévenet, Julien Rey, Marek Vavrusa, Philippe Derreumaux, and Pierre Tufféry. 2016. "PEPFOLD3: Faster de Novo Structure Prediction for Linear Peptides in Solution and in Complex." Nucleic Acids Research 44 (WI): W449-54. https://doi.org/I 0.1093/nar/gkw329.

Larsen, Mette V, Claus Lundegaard, Kasper Lamberth, Soren Buus, Ole Lund, and Morten Nielsen. 2007. "Large-Scale 
bioRxiv preprint doi: https://doi.org/10.1101/795146; this version posted October 7, 2019. The copyright holder for this preprint (which was not certified by peer review) is the author/funder, who has granted bioRxiv a license to display the preprint in perpetuity. It is made available under aCC-BY-NC-ND 4.0 International license.

Validation of Methods for Cytotoxic T-Lymphocyte Epitope Prediction.” BMC Bioinformatics 8 (I): 424. https://doi.org/I0.I I86/I47I-2/05-8-424.

Laskowski, R. A., M. W. MacArthur, D. S. Moss, and J. M. Thornton. 1993. "PROCHECK: A Program to Check the Stereochemical Quality of Protein Structures." Journal of Applied Crystallography 26 (2): 283-9I. https://doi.org/I0.1 107/S0021889892009944.

Lee, Hye-Mi, Dong-Min Shin, Dae-Kyoung Choi, Zee-Won Lee, Ki-Hye Kim, Jae-Min Yuk, Chang Deok Kim, JeungHoon Lee, and Eun-Kyeong Jo. 2009. "Innate Immune Responses to Mycobacterium Ulcerans via Toll-like Receptors and Dectin-I in Human Keratinocytes." Cellular Microbiology II (4): 678-92. https://doi.org/I0.I I I I/j. I462-5822.2009.01285.x.

Lennerz, Volker, Stefanie Gross, Elisa Gallerani, Cristiana Sessa, Nicolas Mach, Steffen Boehm, Dagmar Hess, et al. 2014. "Immunologic Response to the Survivin-Derived Multi-Epitope Vaccine EMD640744 in Patients with Advanced Solid Tumors." Cancer Immunology, Immunotherapy 63 (4): 38I-94. https://doi.org/10.1007/s00262-0I31516-5.

Li, Weidang, Medha D Joshi, Smita Singhania, Kyle H Ramsey, and Ashlesh K Murthy. 20I4. "Peptide Vaccine: Progress and Challenges." Vaccines 2 (3): 5I5-36. https://doi.org/I0.3390/vaccines20305I5.

Lin, Xiaoyun, Shao Chen, Xiangyang Xue, Lijun Lu, Shanli Zhu, Wenshu Li, Xiangmin Chen, et al. 2016. "Chimerically Fused Antigen Rich of Overlapped Epitopes from Latent Membrane Protein 2 (LMP2) of Epstein-Barr Virus as a Potential Vaccine and Diagnostic Agent." Cellular and Molecular Immunology I3 (4): 492-50I. https://doi.org// 0.1038/cmi.2015.29.

Lovell, Simon C., Ian W. Davis, W. Bryan Arendall, Paul I. W. de Bakker, J. Michael Word, Michael G. Prisant, Jane S. Richardson, and David C. Richardson. 2003. "Structure Validation by $C \alpha$ Geometry: $\varphi, \psi$ and C $\beta$ Deviation." Proteins: Structure, Function, and Bioinformatics 50 (3): 437-50. https://doi.org// 0.1002/prot. 10286.

Lu, Chenyang, Shan Meng, Yanxia Jin, Wanggang Zhang, Zongfang Li, Fang Wang, Feng Wang-Johanning, et al. 2017. "A Novel Multi-Epitope Vaccine from MMSA-I and DKKI for Multiple Myeloma Immunotherapy." British Journal of Haematology 178 (3): 4I3-26. https://doi.org/I0.1 II I/bjh. I 4686.

Luckheeram, Rishi Vishal, Rui Zhou, Asha Devi Verma, and Bing Xia. 2012. "CD4 + T Cells: Differentiation and Functions." Clinical and Developmental Immunology 2012 (March): I-12. https://doi.org/I0.I I55/20I2/925 I35.

Magnan, Christophe N., Arlo Randall, and Pierre Baldi. 2009. "SOLpro: Accurate Sequence-Based Prediction of Protein Solubility.” Bioinformatics 25 (I7): 2200-2207. https://doi.org/I0.1093/bioinformatics/btp386.

Manavalan, Balachandran, Rajiv Gandhi Govindaraj, Tae Hwan Shin, Myeong Ok Kim, and Gwang Lee. 20I8. "IBCE-EL: A New Ensemble Learning Framework for Improved Linear B-Cell Epitope Prediction." Frontiers in Immunology 9 (July): 1695. https://doi.org/I0.3389/fimmu.2018.01695.

Markowitz, V. M., I.-M. A. Chen, K. Palaniappan, K. Chu, E. Szeto, Y. Grechkin, A. Ratner, et al. 20I2. "IMG: The Integrated Microbial Genomes Database and Comparative Analysis System." Nucleic Acids Research 40 (DI): DI I5-22. https://doi.org/I0.1093/nar/gkr I044.

Marsollier, Laurent, Raymond Robert, Jacques Aubry, Jean Paul Saint André, Henri Kouakou, Pierre Legras, Anne Lise Manceau, Chetaou Mahaza, and Bernard Carbonnelle. 2002. "Aquatic Insects as a Vector for Mycobacterium Ulcerans." Applied and Environmental Microbiology 68 (9): 4623-28. https://doi.org/I0.1 I28/AEM.68.9.46234628.2002.

Mathur, Deepika, Satya Prakash, Priya Anand, Harpreet Kaur, Piyush Agrawal, Ayesha Mehta, Rajesh Kumar, Sandeep Singh, and Gajendra P. S. Raghava. 2016. "PEPlife: A Repository of the Half-Life of Peptides." Scientific Reports 6 (I): 36617. https://doi.org/10.1038/srep366I7.

Merritt, Richard W., Edward D. Walker, Pamela L.C. Small, John R. Wallace, Paul D.R. Johnson, M. Eric Benbow, and Daniel A. Boakye. 2010. "Ecology and Transmission of Buruli Ulcer Disease: A Systematic Review." PLoS Neglected Tropical Diseases. https://doi.org/I0.137//journal.pntd.00009II.

Mirza, Muhammad Usman, Shazia Rafique, Amjad Ali, Mobeen Munir, Nazia lkram, Abdul Manan, Outi M. H. Salo-Ahen, and Muhammad Idrees. 2016. "Towards Peptide Vaccines against Zika Virus: Immunoinformatics Combined with Molecular Dynamics Simulations to Predict Antigenic Epitopes of Zika Viral Proteins." Scientific Reports 201666 (December): 37313. https://doi.org/10.1038/srep373/3.

Mitra AK, Mawson AR. 2017. "Neglected Tropical Diseases: Epidemiology and Global Burden." Tropical Medicine and Infectious Disease 2 (3): 36. https://doi.org/ 10.3390/tropicalmed2030036.

Monterrubio-López, Gloria P., Jorge A. González-Y-Merchand, and Rosa Mariá Ribas-Aparicio. 2015. "Identification of Novel Potential Vaccine Candidates against Tuberculosis Based on Reverse Vaccinology." BioMed Research International 2015. https://doi.org//0.1/55/20I5/483I50.

Morla, Sudhir, Aditi Makhija, and Sachin Kumar. 2016. "Synonymous Codon Usage Pattern in Glycoprotein Gene of Rabies Virus." Gene 584 (I): I-6. https://doi.org/I0.1016/j.gene.2016.02.047.

Morris, Garrett M., Ruth Huey, William Lindstrom, Michel F. Sanner, Richard K. Belew, David S. Goodsell, and Arthur J. Olson. 2009. "AutoDock4 and AutoDockTools4: Automated Docking with Selective Receptor Flexibility." Journal of Computational Chemistry 30 (I6): 2785-9I. https://doi.org/I0.1002/jcc.2I 256.

Moutaftsi, Magdalini, Bjoern Peters, Valerie Pasquetto, David C Tscharke, John Sidney, Huynh-Hoa Bui, Howard Grey, 
bioRxiv preprint doi: https://doi.org/10.1101/795146; this version posted October 7, 2019. The copyright holder for this preprint (which was not certified by peer review) is the author/funder, who has granted bioRxiv a license to display the preprint in perpetuity. It is made available under aCC-BY-NC-ND 4.0 International license.

and Alessandro Sette. 2006. "A Consensus Epitope Prediction Approach Identifies the Breadth of Murine TCD8+Cell Responses to Vaccinia Virus." Nature Biotechnology 24 (7): 817-19. https://doi.org//0.1038/nbt/215.

N'krumah, Raymond T A S, Brama Koné, Issaka Tiembre, Guéladio Cissé, Gerd Pluschke, Marcel Tanner, and Jürg Utzinger. 2016. "Socio-Environmental Factors Associated with the Risk of Contracting Buruli Ulcer in Tiassalé, South Côte d'Ivoire: A Case-Control Study." PLoS Neglected Tropical Diseases 10 (I): e0004327. https://doi.org/I0.137I/journal.pntd.0004327.

Nagpal, Gandharva, Salman Sadullah Usmani, Sandeep Kumar Dhanda, Harpreet Kaur, Sandeep Singh, Meenu Sharma, and Gajendra P. S. Raghava. 2017. "Computer-Aided Designing of Immunosuppressive Peptides Based on IL-I0 Inducing Potential." Scientific Reports 7 (I): 4285I. https://doi.org/I0.I038/srep4285I.

Nausch, Norman, Daniel Antwi-Berko, Yusif Mubarik, Kabiru Mohammed Abass, Wellington Owusu, Ellis OwusuDabo, Linda Batsa Debrah, Alexander Yaw Debrah, Marc Jacobsen, and Richard O. Phillips. 2017. "Analysis of Mycobacterium Ulcerans-Specific T-Cell Cytokines for Diagnosis of Buruli Ulcer Disease and as Potential Indicator for Disease Progression." PLoS Neglected Tropical Diseases II (2). https://doi.org/I0.137I/journal.pntd.00054I5.

Nezafat, Navid, Zeinab Karimi, Mahboobeh Eslami, Milad Mohkam, Sanam Zandian, and Younes Ghasemi. 2016. "Designing an Efficient Multi-Epitope Peptide Vaccine against Vibrio Cholerae via Combined Immunoinformatics and Protein Interaction Based Approaches." Computational Biology and Chemistry 62 (June): 82-95. https://doi.org// 0.1016/J.COMPBIOLCHEM.2016.04.006.

Nugent, Timothy, Domenico Cozzetto, and David T Jones. 2014. "Evaluation of Predictions in the CASPIO Model Refinement Category.” Proteins 82 Suppl 2 (Suppl 2): 98-III. https://doi.org/I0.1002/prot.24377.

Oscherwitz, Jon. 2016. "The Promise and Challenge of Epitope-Focused Vaccines." Human Vaccines and Immunotherapeutics. Taylor and Francis Inc. https://doi.org/I0.1080/216455I5.2016.1 I60977.

Panda, Subhamay, and Goutam Chandra. 2012. "Physicochemical Characterization and Functional Analysis of Some Snake Venom Toxin Proteins and Related Non-Toxin Proteins of Other Chordates." Bioinformation 8 (18): 89|96. https://doi.org//0.6026/9732063000889l.

Pandey, Rajan Kumar, Tarun Kumar Bhatt, and Vijay Kumar Prajapati. 2018. "Novel Immunoinformatics Approaches to Design Multi-Epitope Subunit Vaccine for Malaria by Investigating Anopheles Salivary Protein." Scientific Reports 8 (I): II25. https://doi.org/I0.1038/s4I598-018-19456-I.

Petrini, B. 2006. "Mycobacterium Marinum: Ubiquitous Agent of Waterborne Granulomatous Skin Infections." European Journal of Clinical Microbiology \& Infectious Diseases: Official Publication of the European Society of Clinical Microbiology 25 (I0): 609-I3. https://doi.org/I0.1007/s I0096-006-020 I-4.

Phillips, Richard Odame, Delphin Mavinga Phanzu, Marcus Beissner, Kossi Badziklou, Elysée Kalundieko Luzolo, Fred Stephen Sarfo, Wemboo Afiwa Halatoko, et al. 20I5. "Effectiveness of Routine BCG Vaccination on Buruli Ulcer Disease: A Case-Control Study in the Democratic Republic of Congo, Ghana and Togo." PLoS Neglected Tropical Diseases 9 (I). https://doi.org/I0.1371/journal.pntd.0003457.

Plotkin, Stanley, James M Robinson, Gerard Cunningham, Robyn lqbal, and Shannon Larsen. 2017. "The Complexity and Cost of Vaccine Manufacturing - An Overview." Vaccine 35 (33): 4064-7I. https://doi.org/10.1016/j.vaccine.2017.06.003.

Pluschke, Gerd, and Katharina Röltgen. 2015. "Epidemiology and Disease Burden of Buruli Ulcer: A Review." Research and Reports in Tropical Medicine, November, 59. https://doi.org//0.2147/rrtm.s62026.

Ponomarenko, Julia, Huynh-Hoa Bui, Wei Li, Nicholas Fusseder, Philip E Bourne, Alessandro Sette, and Bjoern Peters. 2008. "ElliPro: A New Structure-Based Tool for the Prediction of Antibody Epitopes." BMC Bioinformatics 9 (I): 5I4. https://doi.org/|0.II86/I47|-2/05-9-5I4.

Prévot, Ghislaine, Eliane Bourreau, Herve Pascalis, Roger Pradinaud, Audrey Tanghe, Kris Huygen, and Pascal Launois. 2004. "Differential Production of Systemic and Intralesional Gamma Interferon and Interleukin-I 0 in Nodular and Ulcerative Forms of Buruli Disease." Infection and Immunity 72 (2): 958-65. https://doi.org/I 0.I I 28/IAI.72.2.958965.2004.

Quek, Tricia Y.J., Eugene Athan, Margaret J. Henry, Julie A. Pasco, Jane Redden-Hoare, Andrew Hughes, and Paul D.R. Johnson. 2007. "Risk Factors for Mycobacterium Ulcerans Infection, Southeastern Australia." Emerging Infectious Diseases I3 (I I): I66I-66. https://doi.org/I0.320I/eidI3II.06I206.

Rahmani, Abolfazl, Masoud Baee, Maryam Rostamtabar, Ahmad Karkhah, Solmaz Alizadeh, Mehdi Tourani, and Hamid Reza Nouri. 2019. "Development of a Conserved Chimeric Vaccine Based on Helper T-Cell and CTL Epitopes for Induction of Strong Immune Response against Schistosoma Mansoni Using Immunoinformatics Approaches." International Journal of Biological Macromolecules 141 (August): 125-36. https://doi.org// 0.1016/j.ijbiomac.2019.08.259.

Raines, Ronald T., Mark McCormick, Thomas R. Van Oosbree, and Robert C. Mierendorf. 2000. "[23] The S tag Fusion System for Protein Purification.” In , 362-76. https://doi.org/I0.1016/S0076-6879(00)26065-5.

Ramachandran, G. N., C. Ramakrishnan, and V. Sasisekharan. 1963. "Stereochemistry of Polypeptide Chain Configurations." Journal of Molecular Biology. https://doi.org/I0.1016/S0022-2836(63)80023-6.

Rapin, Nicolas, Ole Lund, Massimo Bernaschi, and Filippo Castiglione. 2010. "Computational Immunology Meets 
bioRxiv preprint doi: https://doi.org/10.1101/795146; this version posted October 7, 2019. The copyright holder for this preprint (which was not certified by peer review) is the author/funder, who has granted bioRxiv a license to display the preprint in perpetuity. It is made available under aCC-BY-NC-ND 4.0 International license.

Bioinformatics: The Use of Prediction Tools for Molecular Binding in the Simulation of the Immune System." Edited by Vladimir Brusic. PLoS ONE 5 (4): e9862. https://doi.org/I0.137//journal.pone.0009862.

Ravenel, M. P. 1928. "La Vaccination Préventive Contre La Tuberculose Par Le 'BCG.” American Journal of Public Health and the Nations Health 18 (8): 1075.

Saadi, Mahdiye, Ahmad Karkhah, and Hamid Reza Nouri. 2017. "Development of a Multi-Epitope Peptide Vaccine Inducing Robust T Cell Responses against Brucellosis Using Immunoinformatics Based Approaches." Infection, Genetics and Evolution: Journal of Molecular Epidemiology and Evolutionary Genetics in Infectious Diseases 5 I: 227-34. https://doi.org/I0.1016/j.meegid.2017.04.009.

Sampson, Samantha L. 201 I. "Mycobacterial PE/PPE Proteins at the Host-Pathogen Interface." Clinical \& Developmental Immunology 20 I I: 497203. https://doi.org/I 0.1 I55/20I I/497203.

Sears, Alison V, and Roderick J Hay. 2015. "Buruli Ulcer - a Rapidly Changing Scene." Acta Dermato-Venereologica 95 (4): 387-88. https://doi.org// 0.2340/000 I5555-1943.

Sharp, P M, and W H Li. 1987. "The Codon Adaptation Index--a Measure of Directional Synonymous Codon Usage Bias, and Its Potential Applications." Nucleic Acids Research 15 (3): I28I-95. http://www.ncbi.nlm.nih.gov/pubmed/3547335.

Shey, Robert Adamu, Stephen Mbigha Ghogomu, Kevin Kum Esoh, Neba Derrick Nebangwa, Cabirou Mounchili Shintouo, Nkemngo Francis Nongley, Bertha Fru Asa, Ferdinand Njume Ngale, Luc Vanhamme, and Jacob Souopgui. 2019. "In-Silico Design of a Multi-Epitope Vaccine Candidate against Onchocerciasis and Related Filarial Diseases." Scientific Reports 9 (I): 4409. https://doi.org/I 0.1038/s41598-019-40833-x.

Simpson, Hope, Kebede Deribe, Earnest Njih Tabah, Adebayo Peters, Issaka Maman, Michael Frimpong, Edwin Ampadu, et al. 2019. "Mapping the Global Distribution of Buruli Ulcer: A Systematic Review with Evidence Consensus." The Lancet Global Health 7 (7): e912-22. https://doi.org/I0.1016/S22 I4-I09X(19)30I7I-8.

Singh, Avishek, William John Hannan McBride, Brenda Govan, Mark Pearson, and Scott A. Ritchie. 20I9. "A Survey on Mycobacterium Ulcerans in Mosquitoes and March Flies Captured from Endemic Areas of Northern Queensland, Australia." PLoS Neglected Tropical Diseases I3 (2). https://doi.org/I0.I37//journal.pntd.0006745.

Stinear, Timothy P., Torsten Seemann, Sacha Pidot, Wafa Frigui, Gilles Reysset, Thierry Garnier, Guillaume Meurice, et al. 2007. "Reductive Evolution and Niche Adaptation Inferred from the Genome of Mycobacterium Ulcerans, the Causative Agent of Buruli Ulcer." Genome Research 17 (2): 192-200. https://doi.org/ I 0.I I I/gr.5942807.

Tanghe, Audrey, Jean Pierre Dangy, Gerd Pluschke, and Kris Huygen. 2008. "Improved Protective Efficacy of a SpeciesSpecific DNA Vaccine Encoding Mycolyl-Transferase Ag85A from Mycobacterium Ulcerans by Homologous Protein Boosting." PLoS Neglected Tropical Diseases 2 (3). https://doi.org/10.137I/journal.pntd.0000I 99.

Torrado, Egídio, Sarojini Adusumilli, Alexandra G. Fraga, Pamela L.C. Small, Antonio G. Castro, and Jorge Pedrosa. 2007. "Mycolactone-Mediated Inhibition of Tumor Necrosis Factor Production by Macrophages Infected with Mycobacterium Ulcerans Has Implications for the Control of Infection.” Infection and Immunity 75 (8): 3979-88. https://doi.org/I 0.I I 28/IAI.00290-07.

Trott, Oleg, and Arthur J. Olson. 2009. "AutoDock Vina: Improving the Speed and Accuracy of Docking with a New Scoring Function, Efficient Optimization, and Multithreading." Journal of Computational Chemistry 3I (2): NA-NA. https://doi.org//0.1002/jcc.21334.

Vangone, Anna, and Alexandre M.J.J. Bonvin. 20I5. "Contacts-Based Prediction of Binding Affinity in Protein-Protein Complexes.” ELife 4 (JULY20 I5). https://doi.org/I0.7554/eLife.07454.

Walsh, Douglas S, Wayne M Meyers, Francoise Portaels, Joshua E Lane, Duangrat Mongkolsirichaikul, Kittinun Hussem, Panita Gosi, and Khin Saw Aye Myint. 2005. "High Rates of Apoptosis in Human Mycobacterium Ulcerans Culture-Positive Buruli Ulcer Skin Lesions." The American Journal of Tropical Medicine and Hygiene 73 (2): 4I0-15. http://www.ncbi.nlm.nih.gov/pubmed/I6I036I3.

Wang, Peng, John Sidney, Courtney Dow, Bianca Mothé, Alessandro Sette, and Bjoern Peters. 2008. "A Systematic Assessment of MHC Class II Peptide Binding Predictions and Evaluation of a Consensus Approach." PLoS Computational Biology 4 (4): el 000048 . https://doi.org/I0.137I/journal.pcbi. I000048.

Wang, Peng, John Sidney, Yohan Kim, Alessandro Sette, Ole Lund, Morten Nielsen, and Bjoern Peters. 20I0. "Peptide Binding Predictions for HLA DR, DP and DQ Molecules." BMC Bioinformatics II (I): 568. https://doi.org/I0.II86/I47I-2105-II-568.

Wiederstein, M., and M. J. Sippl. 2007. "ProSA-Web: Interactive Web Service for the Recognition of Errors in ThreeDimensional Structures of Proteins." Nucleic Acids Research 35 (Web Server): W407-10. https://doi.org//0.1093/nar/gkm290.

Wilkins, M R, E Gasteiger, A Bairoch, J C Sanchez, K L Williams, R D Appel, and D F Hochstrasser. 1999. "Protein Identification and Analysis Tools in the ExPASy Server." Methods in Molecular Biology (Clifton, N.J.) II 2: 53I-52. http://www.ncbi.nlm.nih.gov/pubmed/I0027275.

Xue, Li C., Joao Pglm Rodrigues, Panagiotis L. Kastritis, Alexandre Mjj Bonvin, and Anna Vangone. 2016. "PRODIGY: A Web Server for Predicting the Binding Affinity of Protein-Protein Complexes.” Bioinformatics 32 (23): 3676-78. https://doi.org//0.1093/bioinformatics/btw5/4.

Yasmin, T., and A. H. M. Nurun Nabi. 2016. "B and T Cell Epitope-Based Peptides Predicted from Evolutionarily 
bioRxiv preprint doi: https://doi.org/10.1101/795146; this version posted October 7, 2019. The copyright holder for this preprint (which was not certified by peer review) is the author/funder, who has granted bioRxiv a license to display the preprint in perpetuity. It is made available under aCC-BY-NC-ND 4.0 International license.

Conserved and Whole Protein Sequences of Ebola Virus as Vaccine Targets." Scandinavian Journal of Immunology 83 (5): 32 I-37. https://doi.org/ I0.1 I I I/sji. 2425.

Yeboah-Manu, Dorothy, Elisabetta Peduzzi, Ernestina Mensah-Quainoo, Adwoa Asante-Poku, David Ofori-Adjei, Gerd Pluschke, and Claudia A Daubenberger. 2006. "Systemic Suppression of Interferon-Gamma Responses in Buruli Ulcer Patients Resolves after Surgical Excision of the Lesions Caused by the Extracellular Pathogen Mycobacterium Ulcerans." Journal of Leukocyte Biology 79 (6): II50-56. https://doi.org/10.1 I89/jlb. 100558 I.

Yin, Dehui, Li Li, Xiuling Song, Han Li, Juan Wang, Wen Ju, Xiaofeng Qu, et al. 2016. "A Novel Multi-Epitope Recombined Protein for Diagnosis of Human Brucellosis." BMC Infectious Diseases 16 (I). https://doi.org/I0.1 I86/s I 2879-016-I552-9.

Yip, Marcus J, Jessica L Porter, Janet A M Fyfe, Caroline J Lavender, Françoise Portaels, Martha Rhodes, Howard Kator, Angelo Colorni, Grant A Jenkin, and Tim Stinear. 2007. "Evolution of Mycobacterium Ulcerans and Other Mycolactone-Producing Mycobacteria from a Common Mycobacterium Marinum Progenitor." Journal of Bacteriology I89 (5): 202 I-29. https://doi.org/ I0.I I 28/JB.0I442-06.

Zhang, Jian, Xiaowei Zhao, Pingping Sun, Bo Gao, and Zhiqiang Ma. 20I4. "Conformational B-Cell Epitopes Prediction from Sequences Using Cost-Sensitive Ensemble Classifiers and Spatial Clustering." BioMed Research International 2014. https://doi.org/I0.1I55/2014/6892I9.

Zhang, Lifang. 2018. "Multi-Epitope Vaccines: A Promising Strategy against Tumors and Viral Infections." Cellular and Molecular Immunology I5 (2): 182-84. https://doi.org/10.1038/cmi.2017.92.

Zhu, Jinfang, and William E. Paul. 2008. "CD4 T Cells: Fates, Functions, and Faults." Blood II2 (5): I557-69. https://doi.org//0.1 I82/blood-2008-05-078154. 